Article

\title{
Development of New High-Performance Biphenyl and Terphenyl Derivatives as Versatile Photoredox Photoinitiating Systems and Their Applications in 3D Printing Photopolymerization Processes
}

\author{
Wiktoria Tomal $^{1}$ (D), Maciej Pilch ${ }^{1}$, Anna Chachaj-Brekiesz ${ }^{2}$ (D) and Joanna Ortyl ${ }^{1,3, *(D)}$ \\ 1 Cracow University of Technology, Faculty of Chemical Engineering and Technology, Warszawska 24, \\ 31-155 Cracow, Poland \\ 2 Jagiellonian University, Faculty of Chemistry, Gronostajowa 2, 30-387 Cracow, Poland \\ 3 Photo HiTech Ltd., Bobrzyńskiego 14, 30-348 Cracow, Poland \\ * Correspondence: jortyl@chemia.pk.edu.pl
}

Received: 2 September 2019; Accepted: 28 September 2019; Published: 1 October 2019

check for updates

\begin{abstract}
Novel 2-amino-4-methyl-6-phenyl-benzene-1,3-dicarbonitrile derivatives were proposed as photosensitizes of iodonium salt for a highly effective bimolecular photoinitiating system upon soft irradiation conditions under long-wave ultraviolet (UV-A) and visible light. Remarkably, these structures are highly versatile, allowing access to photoinitiating systems for the free-radical polymerization of acrylates, the cationic photopolymerization of epoxides, glycidyl, and vinyl ethers, the synthesis of interpenetrated polymer networks (IPNs) and the thiol-ene photopolymerization processes. Excellent polymerization profiles for all of the monomers, along with the high final conversions, were obtained. The initiation mechanisms of these bimolecular systems based on the 2-amino-4-methyl-6-phenyl-benzene-1,3-dicarbonitrile derivatives were investigated using the real-time FT-IR technique, steady-state photolysis, fluorescence experiments, theoretical calculations of molecular orbitals, and electrochemical analysis. Moreover, the 2-amino-4-methyl-6-phenyl-benzene-1,3-dicarbonitrile derivatives were investigated as a type II free-radical photoinitiator with amine. It was confirmed that the 2-amino-4-methyl-6-phenyl-benzene-1,3-dicarbonitrile derivatives, in combination with different types of additives, e.g., amine as co-initiator or in the presence of onium salt, can act as a bimolecular photoinitiating system via the photo-reduction or photo-oxidation pathways, respectively.
\end{abstract}

Keywords: photo-reduction; photo-oxidation; cationic photopolymerization; free-radical photopolymerization; copolymerization; IPNs; 3D printing

\section{Introduction}

The field of photopolymerization has been one of the most widely and rapidly growing industries in recent years [1,2]. Thus, these materials have found widespread use in the coating industry [3,4], printing inks [5], pressure-sensitive adhesives, including structural adhesives [6,7], photolithography [8,9], medicine [10] for obtaining hydrogel polymeric materials [11,12], and dentistry in photocurable fillings $[13,14]$. Moreover, the light-induced processes play a key role in the microelectronics [15] and electronics industry by applying photocured conductive adhesives or by creating printed circuits [16]. Photopolymerization is also useful in the automotive industry [17], using light for photocurable coatings applied to selected elements of the car [18]. Another currently developing and interesting use of photoinduced processes of polymerization is the manufacture of (holographic) optical elements [19] and microfluidic devices [20,21]. Photopolymerization processes have also succeeded in designing and 
forming three-dimensional (3D) models [22] in 3D printing stereolithography (SLA—stereolithography apparatus) [23], DLP (direct light processing) [24], and the rapidly developing CLIPTM (continuous liquid interface production) method [25]. All of the above-presented examples of applications for photopolymerization are only an indication of the wide spectrum of possibilities for the development of innovative photocurable polymeric materials created by the photochemistry of polymers.

The popularity of photopolymerization in so many areas is principally related to the several advantages of this process. First of all, the main advantage of this process is high speed, as it can be completed even within a few seconds. Additionally, it provides the possibility of conducting photopolymerization processes at ambient temperature, which permits the coating of heat-sensitive substrates such as wood and plastics. Furthermore, the use of solvent-free formulations makes the preparation of polymeric materials by means of the photoinduced polymerization process one of the most efficient photochemical technologies. For these reasons, in recent years, much attention has been paid to the design and manufacture of photoinitiating systems, which will be effective on many levels: They will demonstrate universality, i.e., the effectiveness of the initiation of polymerization occurring according to the free-radical and cationic photopolymerization mechanisms. From a practical point of view, the basic photocurable systems are (meth)acrylic resins, polymerizing according to the free-radical mechanism [26]. It is worth mentioning that, compared to cationic photopolymerization, free-radical initiation is more advanced mainly due to the availability of a wider range of monomers and photoinitiators. Due to the high reactivity of these monomers and the possibility of modification of the ester chain, the materials obtained as a result of the polymerization of these raw materials are characterized by various properties. Photoinitiators of the free-radical polymerization process are compounds that generate radicals to initiate a chemical reaction under the influence of light [27]. From a practical point of view, two types of photoinitiators for free-radical polymerization are used. These two types of initiators differ in their mechanism for the generation of reactive free radicals: Type I radical photoinitiators are unimolecular photoinitiators, while type II are mostly bimolecular radical photoinitiators. Type I photoinitiators undergo homolytic bond cleavage from the triplet state following light excitation, generating two free radicals that start the polymerization. Type II photoinitiators are a combination of two or more component photoinitiating systems with molecules, and form relatively long-lived excited triplet states capable of undergoing hydrogen-absorption or electron/proton transfer reactions with co-initiator molecules. Nevertheless, the main disadvantage of free-radical photopolymerization is oxygen inhibition, which reduces the efficiency of polymerization [28]. The second type of photopolymerization is cationic polymerization, which is a technique that may be used to polymerize important classes of monomers which cannot be polymerized by free-radical means, such as epoxides, vinyl ethers, propenyl ethers, siloxanes, oxetanes, cyclic acetals and formals, cyclic sulfides, lactones, and lactams [29]. These monomers include both unsaturated monomers that undergo chain polymerization through the carbon-carbon double bonds and cyclic monomers that undergo ring-opening polymerization. Nevertheless, cationic photopolymerization is applied mainly to epoxy monomers, vinyl ethers, and their derivatives in the industry $[30,31]$. In the photochemical industry, onium salts and mainly diaryliodonium and triarylsulfonium salts [32,33], in which protons are the particles initiating the process and active centers are carbocations or onion ions [34], are used as efficient photoinitiators for the cationic photopolymerization process. In contrast to free-radical photopolymerization, which experiences rapid termination of the polymerization process when the light is turned off (due to radical-radical termination reactions), the cationic polymerization processes proceeds long after irradiation has ceased, until nearly all of the monomer has been consumed [35]. Moreover, the indisputable advantage of cationic photopolymerization is its living character and resistance to the inhibitory effect of atmospheric oxygen [36]. These features of cationic polymerization indicate its attractive application prospects. Nevertheless, cationic photopolymerization still has some weaknesses. In contrast to free-radical photoinitiators, fewer cationic photoinitiators are commercially available. 
From an industrial point of view, an interesting variation of the photopolymerization process is a hybrid photochemical-initiated polymerization, which combines different polymerization mechanisms or different types of materials [37]. Essentially, there are two types of hybrid systems, one is a system of monomers (e.g., vinyl and acrylic) polymerizing according to different mechanisms, i.e., radical and cationic, which usually takes place using two different photoinitiators. As a consequence, this leads to so-called interpenetrating polymer networks (IPNs), which are formed as a result of the simultaneous polymerization of two multifunctional monomers [38,39]. The second type of hybrid system is a system of different polymeric monomers with one common mechanism (e.g., vinyl monomer chain and cycloaliphatic epoxy monomer catatonically polymerizing with ring opening) and, thus, use one type of photoinitiator [40]. Indeed, these different photopolymerization modes often use specific or adapted initiating systems. The need to add two different types of photoinitiators often causes problems with the choice of light source for the process of photopolymerization of the IPNs, because different photoinitiators have different characteristics of absorption, which affects the effectiveness of initiation. For example, some radical photoinitiators can initiate in visible light, while cationic photoinitiators are not adapted for this purpose. IPN photopolymerization carried out in this way causes problems at the stage of selecting a photoinitiating system; however, this type of process allows to obtain materials with completely innovative functional, mechanical, and strength properties, which are not available when conducting photopolymerization of one type of monomer. For this reason, the development of efficient versatile photoinitiating systems remains a great challenge.

Taking all of the above into consideration, there is a need to design new high-performance photoinitiating systems with absorption characteristics compatible with the emission characteristics of low power LED light sources to provide photoinitiation of free-radical and cationic polymerization simultaneously, ensuring the versatility of operation regardless of the monomers selected. In this paper, we describe bimolecular photoinitiating systems operating in the long-wave ultraviolet (UV-A) and visible light range, where 2-amino-4-methyl-6-phenyl-benzene-1,3-dicarbonitrile derivatives were selected as the effective photosensitizes. In order to verify the applicability of the biphenyl derivatives, their spectroscopic characteristics were determined. More specifically, the 2-amino-4-methyl-6-phenyl-benzene-1,3-dicarbonitrile derivatives are proposed as bimolecular photoredox initiators with iodonium salt to induce the formation of radicals and cations as reactive species for both the free-radical polymerization of acrylates and the cationic polymerization of epoxides and glycidyles under UV-A and visible light. The photochemical mechanisms were studied through steady-state photolysis, fluorescence experiments, theoretical calculations of molecular orbitals, and electrochemical analysis. This approach allowed the study of the structure/reactivity/efficiency relationships of the investigated biphenyl derivatives as photosensitizes of iodonium salt in cationic, free-radical, and IPN photopolymerization under low intensity LED light sources. Moreover, the 2-amino-4-methyl-6-phenyl-benzene-1,3-dicarbonitrile derivatives were investigated as a type II free-radical photoinitiator with amine. It was confirmed that the 2-amino-4-methyl-6-phenyl-benzene-1,3-dicarbonitrile derivatives, in combination with different types of additives, e.g., amine as co-initiator or in the presence of onium salt, can act as a bimolecular photoinitiating system via the photo-reduction or photo-oxidation pathways, respectively. Additionally, the use of these new high-performance bimolecular photoinitiating systems in 3D printing was also investigated. Different types of compositions for 3D printing are proposed, including IPN systems and copolymers.

\section{Results and Discussion}

\subsection{Spectroscopic Characteristics of Investigated Compounds}

The UV-Vis spectra of the 2-amino-4-methyl-6-phenyl-benzene-1,3-dicarbonitrile derivatives were recorded in acetonitrile to determine the maxima of the absorption characteristics and the corresponding extinction coefficient at an absorption maximum wavelength (Table 1 and Figure 1a,b). All investigated 
biphenyl derivatives are characterized by good molar extinction coefficients in the UV-Vis range, which reach values around $5000-15,000\left[\mathrm{dm}^{3} \cdot \mathrm{mol}^{-1} \cdot \mathrm{cm}^{-1}\right]$ at an absorption maximum wavelength. Moreover, the absorption characteristic range of the 2-amino-4-methyl-6-phenyl-benzene-1,3-dicarbonitrile derivatives is $425 \mathrm{~nm}$, ensuring a great compatibility with the emission spectra of long ultraviolet sources of light (e.g., with $\lambda_{\text {em-max }}$ at $365 \mathrm{~nm}$ UV-LED) and visible sources of light (e.g., with $\lambda_{\text {em-max }}$ at $405 \mathrm{~nm}$ Vis-LED) (Table 1).

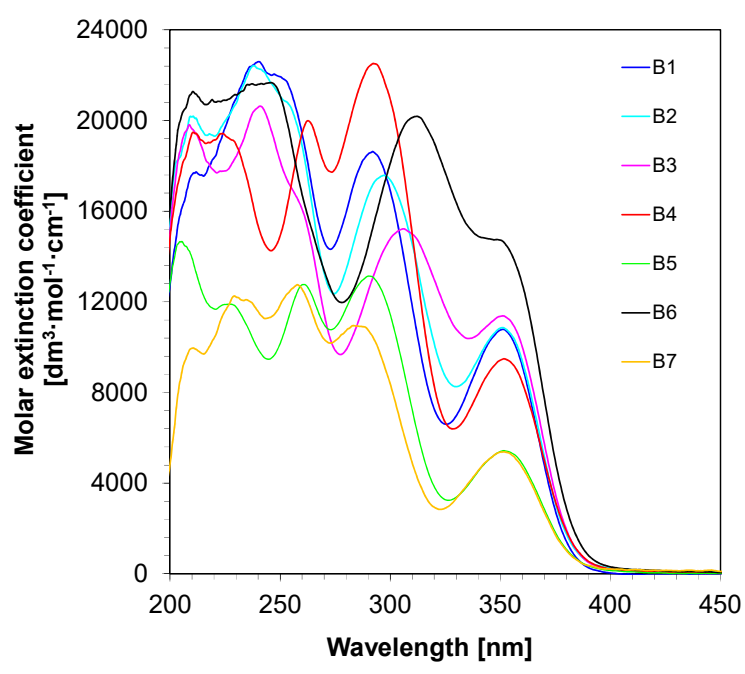

(a)

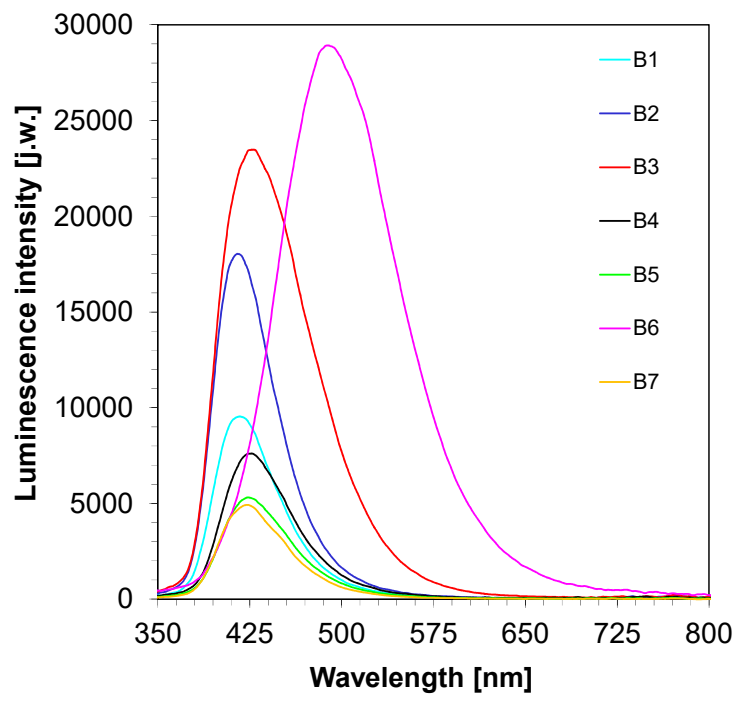

(c)

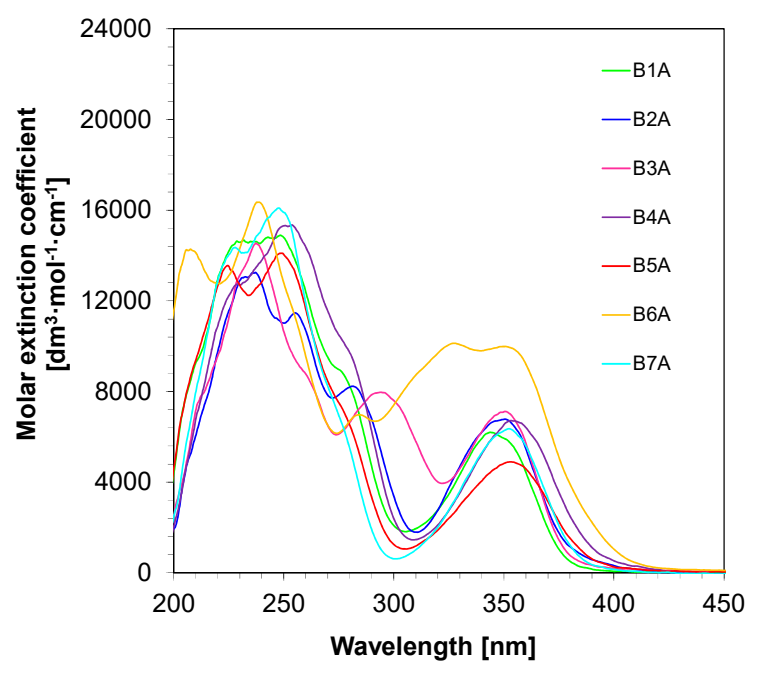

(b)

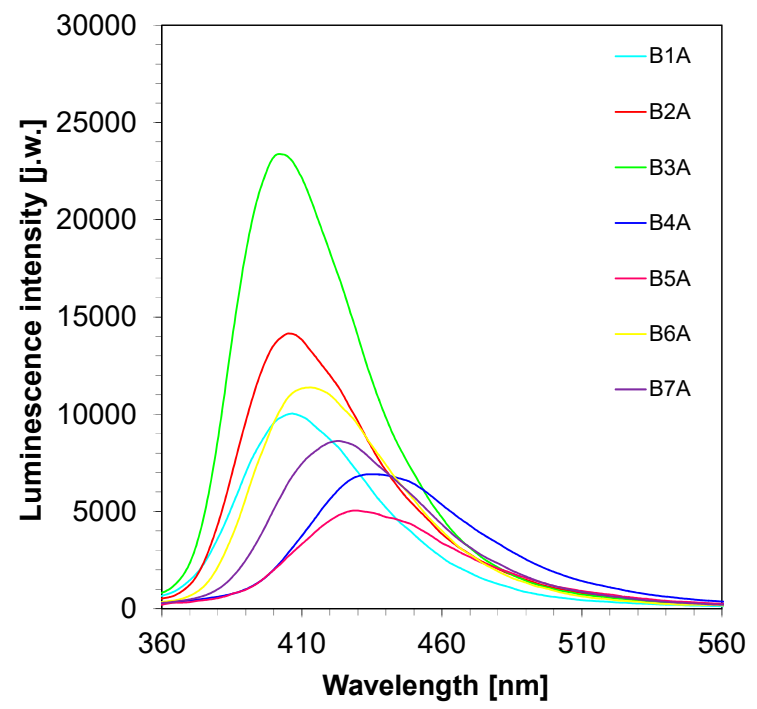

(d)

Figure 1. Spectroscopic properties of the 2-amino-4-methyl-6-phenyl-benzene-1,3-dicarbonitrile derivatives. (a) UV-visible absorption spectra of series 1 in acetonitrile; (b) UV-visible absorption spectra of series 2 in acetonitrile; (c) fluorescence spectra of series 1 in acetonitrile in extinction $320 \mathrm{~nm}$ and integration time 1s; (d) fluorescence spectra of series 2 in acetonitrile in extinction $320 \mathrm{~nm}$ and integration time $1 \mathrm{~s}$.

Therefore, their extinction coefficient is relatively high, in the $350-425 \mathrm{~nm}$ spectral range, ensuring a fairly good overlap with the emission spectra of the LED@365 nm and LED@405 nm used in this work. In order to comprehensively determine the spectroscopic characteristics, the fluorescence spectra of the investigated compounds in acetonitrile were also measured. As given in Figure 1c,d, all proposed compounds exhibit fluorescence in the visible spectrum of a range between $360-700 \mathrm{~nm}$. 
Table 1. Spectral characteristics of the 2-amino-4-methyl-6-phenyl-benzene-1,3-dicarbonitrile derivatives studied in acetonitrile.

\begin{tabular}{|c|c|c|c|c|c|c|c|c|}
\hline & 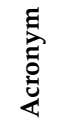 & $\begin{array}{c}\lambda_{\max -a b} \\
{[\mathrm{~nm}]}\end{array}$ & $\begin{array}{c}\varepsilon_{@ \lambda \max -\mathrm{ab}} \\
{\left[\mathrm{dm}^{3} \cdot \mathrm{mol}^{-1} \cdot \mathrm{cm}^{-1}\right]}\end{array}$ & $\begin{array}{c}\varepsilon_{@ \lambda \max -\mathrm{ab}} \\
{\left[\mathrm{dm}^{3} \cdot \mathrm{mol}^{-1} \cdot \mathrm{cm}^{-1}\right]}\end{array}$ & $\begin{array}{c}\mathcal{E}_{@ \lambda \max -a b} \\
{\left[\mathrm{dm}^{3} \cdot \mathrm{mol}^{-1} \cdot \mathrm{cm}^{-1}\right]}\end{array}$ & $\begin{array}{c}\lambda_{\text {max-fluo }} \\
\text { in ACN } \\
{[n m]}\end{array}$ & $\begin{array}{c}I_{\text {max-fluo }} \\
\text { in ACN } \\
\text { [a.u.] }\end{array}$ & $\begin{array}{c}\text { Stokes } \\
\text { Shift } \\
{\left[\mathrm{cm}^{-1}\right]}\end{array}$ \\
\hline \multirow{7}{*}{. } & B1 & 351 & 10,790 & 7000 & 0 & 417 & 9550 & 4475 \\
\hline & B2 & 351 & 10,860 & 7320 & 210 & 415 & 18,040 & 4372 \\
\hline & B3 & 351 & 11,350 & 7970 & 145 & 428 & 23,480 & 5095 \\
\hline & B4 & 352 & 9490 & 6810 & 160 & 426 & 7610 & 4986 \\
\hline & B5 & 352 & 5440 & 3890 & 110 & 424 & 5320 & 4840 \\
\hline & B6 & 341 & 14,840 & 10,410 & 235 & 489 & 28,930 & 8845 \\
\hline & B7 & 352 & 5380 & 3740 & 200 & 423 & 4930 & 4787 \\
\hline \multirow{7}{*}{ 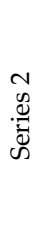 } & B1A & 344 & 3200 & 3130 & 75 & 407 & 10,030 & 4492 \\
\hline & B2A & 350 & 6700 & 4040 & 210 & 405 & 14,150 & 3866 \\
\hline & B3A & 350 & 7120 & 4090 & 183 & 402 & 23,380 & 3645 \\
\hline & B4A & 353 & 6720 & 5730 & 870 & 435 & 6920 & 5335 \\
\hline & B5A & 353 & 4900 & 3920 & 210 & 429 & 5050 & 5024 \\
\hline & B6A & 351 & 9990 & 8010 & 650 & 413 & 11,370 & 4305 \\
\hline & B7A & 353 & 6360 & 4450 & 85 & 423 & 8630 & 4723 \\
\hline
\end{tabular}

Table 1 presents a summary of the spectroscopic properties of the investigated 2-amino-4-methyl-6phenyl-benzene-1,3-dicarbonitrile derivatives. On the basis of the obtained data, Stockes's shift was calculated. The effects of substituents, as well as of the number of benzene rings on the spectroscopic characteristics of the investigated biphenyl derivatives, are noticeable.

\subsection{Performance of the 2-Amino-4-Methyl-6-Phenyl-Benzene-1,3-Dicarbonitrile Derivatives as Photosensitizers for Iodonium Salt in a Bimolecular Photoinitiating System for Cationic Photopolymerization}

The cationic photopolymerization process is particularly interesting and relatively widely used in many applications, as it has several essential practical advantages. The living character of cationic photopolymerization guarantees that the reaction continues to be effective even after the turn-off of the radiation source. Additionally, during this process, oxygen inhibition does not occur. For this reason, in this research, the cationic photopolymerization process of 3,4-epoxycyclohexylmethyl-3,4-epoxycyclohexane-carboxylate monomer (CADE) was carried out under air. The evaluation of the epoxy group content was continuously followed at about $790 \mathrm{~cm}^{-1}$, where the area of the band from the epoxy group decreased during the photopolymerization process. Additionally, a new band ascribed to the formation of the polyether network at $\sim 1080 \mathrm{~cm}^{-1}$ appeared during cationic photopolymerization. Upon irradiation with the UV-A LED source under an emission maximum of $365 \mathrm{~nm}$ (with $\mathrm{I}_{0} \sim 3.77 \mathrm{~mW} / \mathrm{cm}^{2}$ ), the ring opening photopolymerization of the epoxy monomer in the presence of two component initiating systems consisting of biphenyl derivatives and iodonium salt (Speedcure 938$)(0.1 \% / 1 \% \mathrm{w} / \mathrm{w})$ was very efficient in terms of the final epoxy group conversion. The conversion time profiles for the cationic photopolymerization process of the CADE monomer under ultraviolet light conditions are given in Figures 2a and 3a. All investigated biphenyl derivatives can be used as highly effective photosensitizes for iodonium salts during cationic photopolymerization in UV-light conditions. Remarkably, higher values of epoxide monomer conversions were obtained for 2-amino-4-methyl-6-(4-phenylphenyl)-benzene-1,3-dicarbonitrile derivatives (series 1 of biphenyl compounds). 


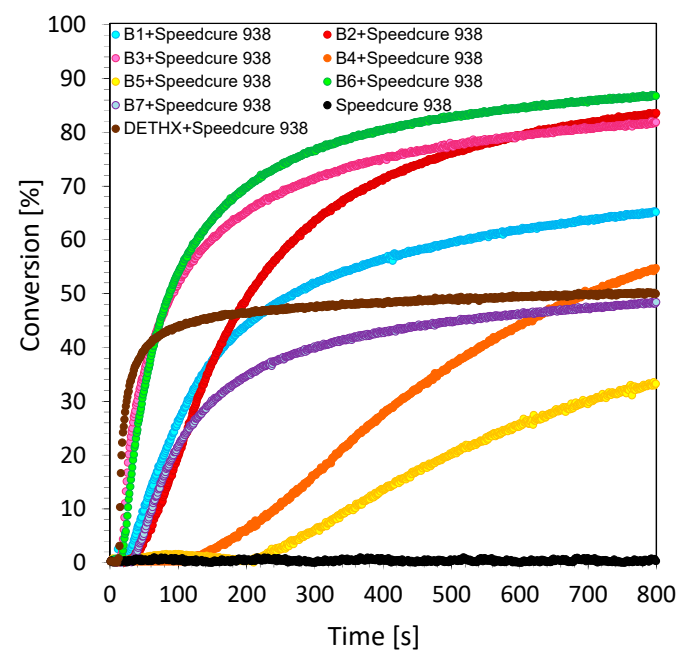

(a)

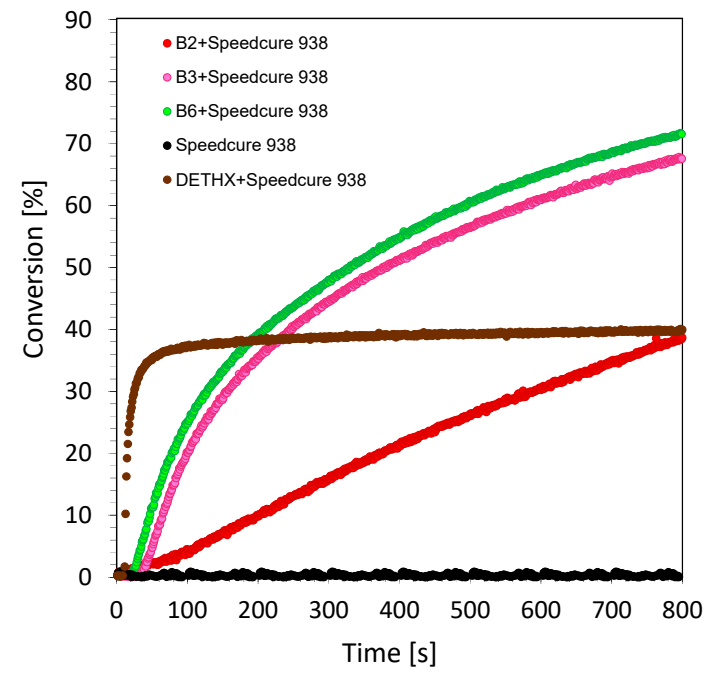

(b)

Figure 2. (a) Cationic photopolymerization profiles (epoxy function conversion vs. irradiation time) initiated by a bimolecular photoinitiating system based on Speedcure $938(1 \% \mathrm{wt}$.) and 2-amino-4-methyl-6-(4-phenylphenyl)benzene-1,3-dicarbonitrile derivatives $(0.1 \% \mathrm{wt}$.) for series 1 (a) under irradiation at $365 \mathrm{~nm}$; (b) under irradiation at $405 \mathrm{~nm}$.

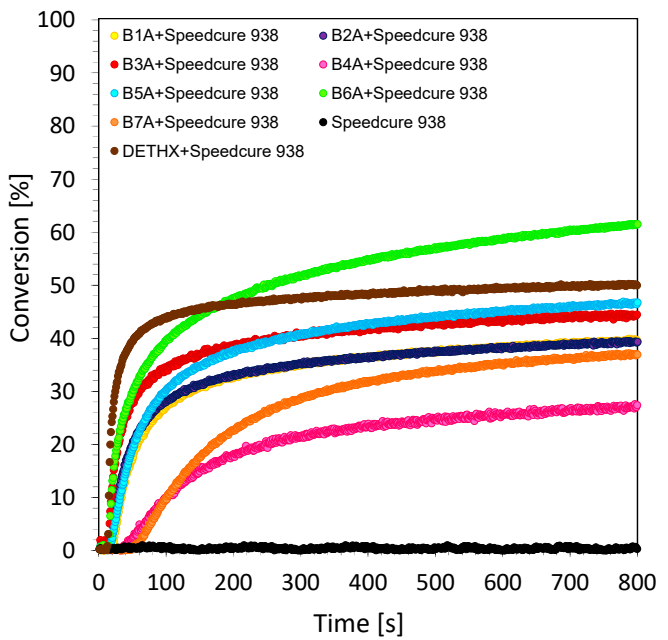

(a)

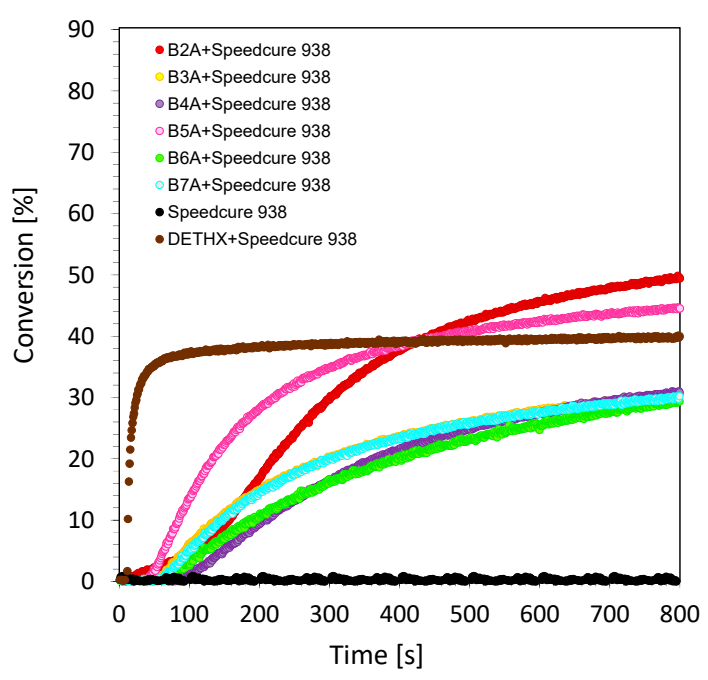

(b)

Figure 3. (a) Cationic photopolymerization profiles (epoxy function conversion vs. irradiation time) initiated by bimolecular photoinitiating system based on Speedcure 938 (1\% wt.) and 2-amino-4-methyl6-(4-phenylphenyl)benzene-1,3-dicarbonitrile derivatives $(0.1 \% \mathrm{wt}$.) for series 2 (a) under irradiation at $365 \mathrm{~nm}$; (b) under irradiation at $405 \mathrm{~nm}$.

Nevertheless, a different situation is observed while carrying out cationic ring opening polymerization, upon irradiation under a visible source of light with the emission maximum at $405 \mathrm{~nm}$ (with $\mathrm{I}_{0} \sim 12.07 \mathrm{~mW} / \mathrm{cm}^{2}$ ). Under this irradiation condition, only several derivatives from series 1 exhibit good performance as visible photosensitizes in two component photoinitiating systems based on iodonium salt (Figure 2b). Derivatives of 2-amino-4-methyl-6-phenyl-benzene-1,3-dicarbonitrile (series 2 of biphenyls) besides the B1A compound, however, can be used as efficient visible photosensitizers (Figure $3 b$ ). This effect is dictated by their structure, which is proven by the absorbance characteristics of those compounds. As shown in Figures 2 and 3, no conversion of the epoxy group was found when 
the sample had no biphenyl derivatives acting as photosensitizes of iodonium salt. As Speedcure 938 has a maximum absorbance at $242 \mathrm{~nm}$ [41,42], the irradiation wavelength was $365 \mathrm{~nm}$ or $405 \mathrm{~nm}$. In this case, Speedcure 938 could not decompose in order to form reactive species to induce the polymerization of epoxide groups. The exact values of epoxy group conversions under ultraviolet and visible light conditions are given in Table 2.

Bisphenol A diglycidyl ether (DGEBA) is an inexpensive and widely used monomer in polymer industry. The price of DGEBA is only a fraction of cycloaliphatic epoxide monomer, 3,4-epoxycyclohexylmethyl-3,4-epoxy-cyclohexane-carboxylate (CADE), widely used in the polymer coating industry. DGEBA is typically employed in condensation network polymerizations with amines [43], amides [44], and anhydrides [45] in order to obtain thermosetting epoxy resins. Bisphenol A diglycidyl ether is also polymerizable by cationic photopolymerization by electron beam sources [46]. This is due to the fact that the cationic photopolymerization of DGEBA is very sluggish $[47,48]$. Furthermore, the high viscosity of DGEBA epoxides makes their handling difficult during the process of preparation for coating. This is caused by poor mixing with other components, e.g., with photoinitiators or photoinitiating systems. The problem caused by the high viscosity of this resin based on Bisphenol A diglycidyl ether was solved by adding to the composition the low-viscosity 1,2-epoxy-3-phenoxypropane monomer (EPXPROP), which acts as a reactive diluent during the cationic photo-copolymerization process of these two types of glycidyle monomers. The compositions consisting of glycidyl ether monomers based on DGEBA and EPXPROP $(70 \% / 30 \% \mathrm{w} / \mathrm{w})$ was investigated using real-time FT-IR. The cationic photopolymerization of this monomer mixture was carried out under air and in ambient room temperature $\left(25^{\circ} \mathrm{C}\right)$ upon irradiation with an ultraviolet UV-LED source of light with maximum emission at $365 \mathrm{~nm}$ and intensity at the surface of the sample of about $\sim 7.97 \mathrm{~mW} / \mathrm{cm}^{2}$. The evaluation of the glycidyl group content was continuously followed at about $915 \mathrm{~cm}^{-1}$, where the area of the band from the epoxy group decreased during the photopolymerization process. The cationic photopolymerization of glycidyl monomers in the presence of bimolecular photoinitiating systems consisting of biphenyl derivatives and iodonium salt $(0.2 \% / 2 \% \mathrm{w} / \mathrm{w})$ was very efficient in terms of the final glycidyl group conversion (Figure $4 a, b)$. The values of conversion were in the range of $81-89 \%$ (Table 2), which is the reason for obtaining a highly cross-linked polymer network.

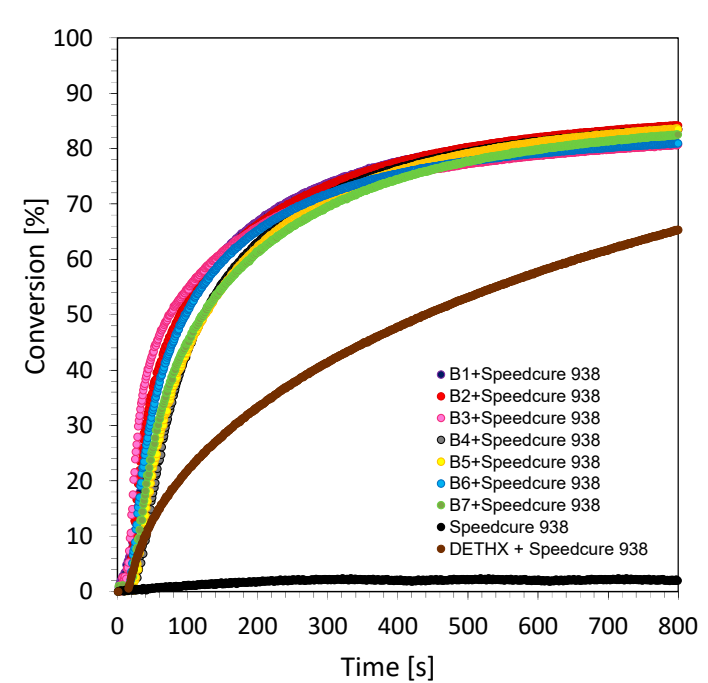

(a)

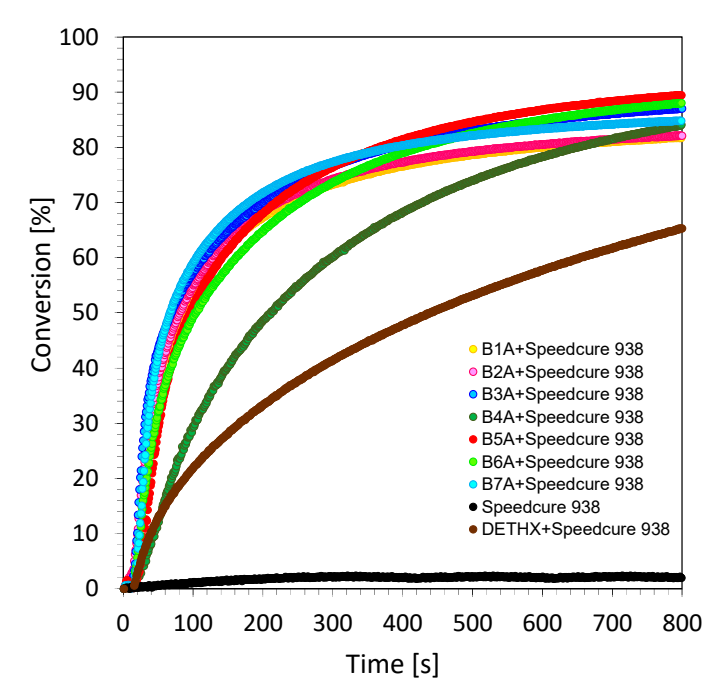

(b)

Figure 4. Cationic photopolymerization profiles DEGDBA/EPXPROP (70/30\% w/w) (glycidyl group function conversion vs. irradiation time) initiated by bimolecular photoinitiating system based on Speedcure 938 (2\% wt.) and biphenyl derivatives ( $0.2 \% \mathrm{wt}$.) under light irradiation at $365 \mathrm{~nm}$ for (a) biphenyl derivatives from series 1, (b) biphenyl derivatives from series 2 . 
Table 2. Summary of functional group conversions of used monomers for various photopolymerization processes, with the use of the 2-amino-4-methyl-6-phenyl-benzene -1,3-dicarbonitrile derivatives.

\begin{tabular}{|c|c|c|c|c|c|c|c|c|}
\hline & & \multicolumn{7}{|c|}{ Conversion $[\%]$} \\
\hline & & \multicolumn{3}{|c|}{ Cationic Photopolymerization } & \multicolumn{4}{|c|}{ Free-Radical Photopolymerization } \\
\hline & \multirow{3}{*}{ 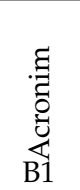 } & \multicolumn{2}{|c|}{$\begin{array}{l}\text { CADE with Iod at } \\
\sim 790 \mathrm{~cm}^{-1}\end{array}$} & \multirow{3}{*}{$\begin{array}{c}\text { Glycidyl } \\
\text { with Iod at } \\
\sim 915 \mathrm{~cm}^{-1} \\
@ 365 \mathrm{~nm}^{\mathrm{c}} \\
83.4\end{array}$} & \multicolumn{2}{|c|}{$\begin{array}{l}\text { TMPTA with Iod at } \\
\quad \sim 1635 \mathrm{~cm}^{-1}\end{array}$} & \multicolumn{2}{|c|}{$\begin{array}{l}\text { TMPTA with EDB at } \\
\sim 1635 \mathrm{~cm}^{-1}\end{array}$} \\
\hline \multirow{8}{*}{. } & & $@ 365 \mathrm{~nm}^{\mathrm{a}}$ & $@ 405 \mathrm{~nm}^{\mathrm{b}}$ & & $@ 365 \mathrm{~nm}^{\mathrm{a}}$ & $@ 405 \mathrm{~nm}^{\mathrm{b}}$ & $@ 365 \mathrm{~nm}^{\mathrm{a}}$ & $@ 405 \mathrm{~nm}^{\mathrm{b}}$ \\
\hline & & 64.9 & NP d & & 52.0 & NPd & 58.6 & NP d \\
\hline & B2 & 83.4 & 38.4 & 84.2 & 51.2 & 35.2 & 54.2 & $\mathrm{NP}^{\mathrm{d}}$ \\
\hline & B3 & 81.6 & 67.3 & 80.7 & 53.4 & 47.7 & 53.3 & 55.8 \\
\hline & $\mathrm{B} 4$ & 54.4 & $\mathrm{NP}^{\mathrm{d}}$ & 83.5 & 49.8 & $\mathrm{NP}^{\mathrm{d}}$ & 52.7 & $\mathrm{NP}^{\mathrm{d}}$ \\
\hline & B5 & 32.2 & $N P^{d}$ & 83.5 & 38.5 & 33.3 & $\mathrm{NP}^{\mathrm{d}}$ & $\mathrm{NP}^{\mathrm{d}}$ \\
\hline & B6 & 86.5 & 71.2 & 81.0 & 53.4 & 47.4 & 58.6 & 50.2 \\
\hline & B7 & 48.2 & $\mathrm{NP}^{\mathrm{d}}$ & 82.5 & 53.2 & 43.7 & 55.6 & 53.8 \\
\hline \multirow{7}{*}{ 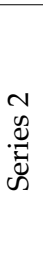 } & B1A & 39.2 & $\mathrm{NP}^{\mathrm{d}}$ & 81.7 & 31.5 & 21.3 & 30.7 & $\mathrm{NP}^{\mathrm{d}}$ \\
\hline & B2A & 39.1 & 49.2 & 82.1 & 37.4 & 23.8 & 47.3 & $\mathrm{NP}^{\mathrm{d}}$ \\
\hline & B3A & 44.2 & 30.4 & 87.0 & 41.9 & 25.2 & 48 & 13.9 \\
\hline & B4A & 27.1 & 30.6 & 84.1 & 38,7 & 37.7 & 48 & 35.2 \\
\hline & B5A & 46.5 & 44.3 & 89.4 & 39.7 & 38.6 & 45.3 & 30.5 \\
\hline & B6A & 61.3 & 29.3 & 88.0 & 51.0 & 44.0 & 55.6 & 40.7 \\
\hline & B7A & 36.7 & 29.9 & 84.8 & 23.1 & 24.0 & 56.1 & 37.4 \\
\hline
\end{tabular}

2.3. Performance of 2-Amino-4-Methyl-6-Phenyl-Benzene-1,3-Dicarbonitrile as Photosensitizer for Iodonium Salt in a Bimolecular Photoinitiating System for Free-Radical Photopolymerization

Radical photopolymerization is one of the most widely used photopolymerizations based on the photochemical initiation of free radicals. The polymerization process under the influence of the applied light is mainly used for acrylate and methacrylate monomers. The reason for their popularity is the availability of different types of (meth)acrylate monomers on the market and their high reactivity, as they polymerize rapidly in the presence of free radicals. Acrylates, however, are not initiated by cationic species, because they have ester groups that act as electron withdrawing groups, decreasing the electron density on the double bond. This leads to a repulsive force between monomers and cationic species. Studies have proved, however, that the developed bimolecular photoinitiating system based on biphenyl derivatives and iodonium salt can act as a dual-type initiating system. In this approach, the dual type means that this type of system can efficiently initiate free-radical and cationic photopolymerization processes, respectively. As confirmation, the free-radical photopolymerization processes of trimethylolpropane triacrylate monomer (TMPTA) were carried out in laminate conditions, to prevent the inhibitory effect of oxygen on the generated radical species. The process was controlled by monitoring the decrease of the maximum area of a band at $1635 \mathrm{~cm}^{-1}$ wavelength, which was responsible for the double bond of the acrylate group content. Conversion time profiles for the two irradiation conditions under long wavelength ultraviolet (UV-A LED @365 nm with the emission intensity on the surface of the sample at about $3.77 \mathrm{~mW} / \mathrm{cm}^{2}$ ) and visible light sources (Vis-LED @405 $\mathrm{nm}$ with the emission intensity on the surface of the sample at about $7.97 \mathrm{~mW} / \mathrm{cm}^{2}$ ) are shown in Figures 5 and 6. The final values of the double bond conversion are given in Table 2. 


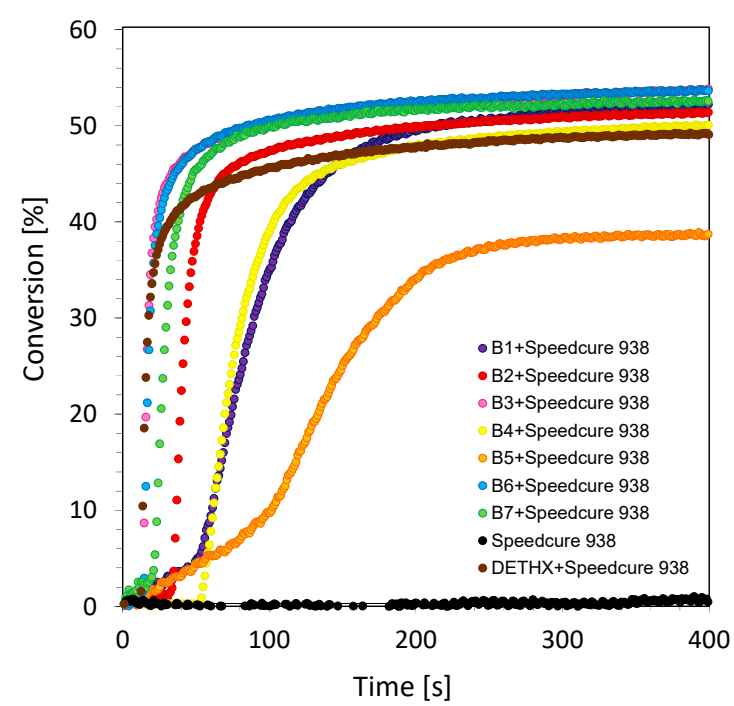

(a)

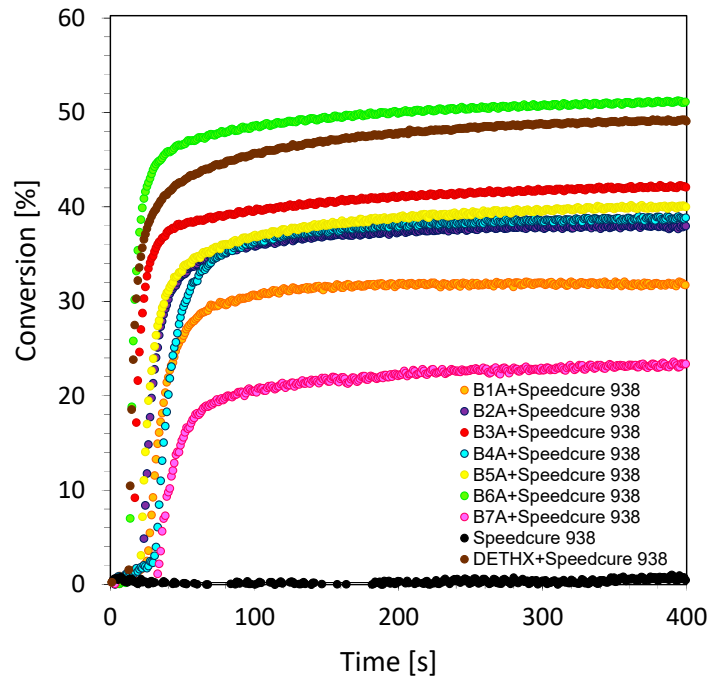

(b)

Figure 5. Free-radical photopolymerization profiles (acrylate function conversion vs. irradiation time) for TMPTA with the bimolecular photoinitiating system based on (a) series 1 of 2-amino-4-methyl-6-(4-phenylphenyl)benzene-1,3-dicarbonitrile derivatives and Speedcure 938 $(0.1 \% / 1 \% \mathrm{w} / \mathrm{w})$ under visible light LED source $365 \mathrm{~nm}$; (b) series 1 of 2-amino-4-methyl-6-(4phenylphenyl)benzene-1,3-dicarbonitrile derivatives and Speedcure $938(0.1 \% / 1 \% \mathrm{w} / \mathrm{w})$ under visible light LED source $365 \mathrm{~nm}$.

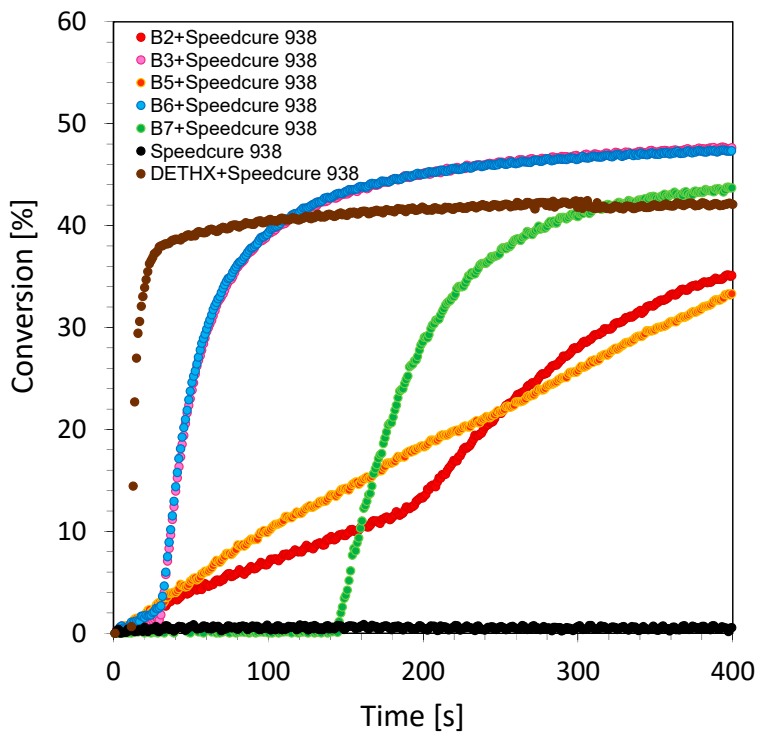

(a)

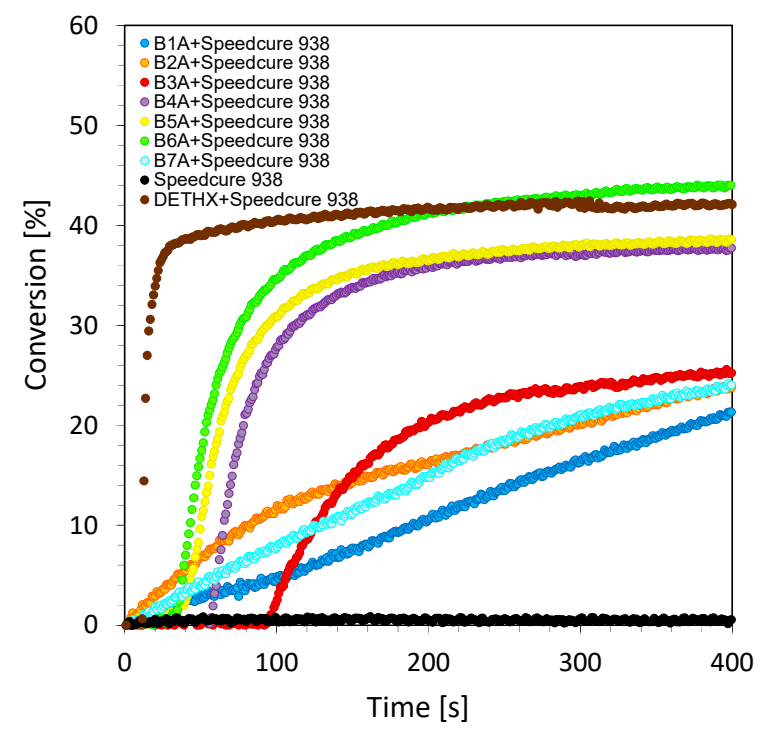

(b)

Figure 6. Free-radical photopolymerization profiles (acrylate function conversion vs. irradiation time) for TMPTA with the bimolecular photoinitiating system based on (a) series 1 of 2-amino-4-methyl-6-(4-phenylphenyl)benzene-1,3-dicarbonitrile derivatives and Speedcure 938 $(0.1 \% / 1 \% \mathrm{w} / \mathrm{w})$ under visible light LED source $405 \mathrm{~nm}$; (b) series 1 of 2-amino-4-methyl-6-(4phenylphenyl)benzene-1,3-dicarbonitrile derivatives and Speedcure $938(0.1 \% / 1 \% \mathrm{w} / \mathrm{w})$ under visible light LED source $405 \mathrm{~nm}$.

From the data obtained during the measurements, it was shown that bimolecular photoinitiating systems, containing biphenyl derivatives and iodonium salt $(0.1 \% / 1 \% \mathrm{w} / \mathrm{w})$, can be used in the free-radical photopolymerization of acrylates, reaching a maximum conversion value 
$\sim 50 \%$. In conclusion, the photosensitization of iodonium salt using 2-amino-4-methyl-6-phenylbenzene-1,3-dicarbonitrile derivatives in the free-radical polymerization of TMPTA is a highly efficient process at $365 \mathrm{~nm}$ and $405 \mathrm{~nm}$. Moreover, the polymerization rate enhancement effect of this process can be easily increased by extending the power of the used LED light sources. It is worth mentioning that diphenyliodonium salt (e.g., Speedcure 938, Figures 5 and 6) alone does not initiate free-radical photopolymerization, indicating the role of biphenyl derivatives as photosensitizers of iodonium salt through the mechanism of photo-oxidizable sensitization of this salt under long-wavelength ultraviolet and visible light regions. This efficient behavior during the free-radical photoinitiation process will be discussed in detail in the mechanistic section of this paper. The usefulness of the developed initiating systems in the radical polymerization process gives us the opportunity to use them as dual initiating systems, which can be utilized for the hybrid photopolymerization processes of different types of monomers. This application will be described in detail in a later part of this manuscript.

\subsection{Performance of 2-Amino-4-Methyl-6-Phenyl-Benzene-1,3-Dicarbonitrile as Bimolecular Free-Radical Photoinitiator Type II}

It was found that the investigated 2-amino-4-methyl-6-phenyl-benzene-1,3-dicarbonitrile derivatives exhibit the ability to initiate photoinduced free-radical polymerization processes according to the photo-reduction mechanism. This was confirmed by real-time FT-IR studies of the radical polymerization process of acrylate TMPTA using free-radical type II initiators based on biphenyl derivatives and amine (EDB). Type II free-radical photoinitiators generate radicals in the presence of co-initiators in a multi-step reaction mechanism. In this case, an amine ethyl 4-(dimethylamino)benzoate (EDB) was used as a co-initiator. Upon illumination, a photosensitizer in the excited state began to interact with a co-initiator that was an electron donor (EDB). In these bimolecular photoinitiating systems, biphenyl derivatives acted as electron acceptors, whereas the main radicals that initiated polymerization formed on those co-initiator molecules. The combination of biphenyl derivatives as photosensitizers and an amine as an electron donor component in this II type free-radical bimolecular initiator is an effective system. The highest values of conversion were obtained for B6/EDB $(0.5 / 1.5 \%$ $\mathrm{w} / \mathrm{w}$ ) from series 1 and for its analogue from series 2, B6A/EDB (0.5/1.5\% w/w) (Figure 7). Such dependence was confirmed by the value of the calculated Gibbs free energy for these two biphenyl compounds (Table 2).
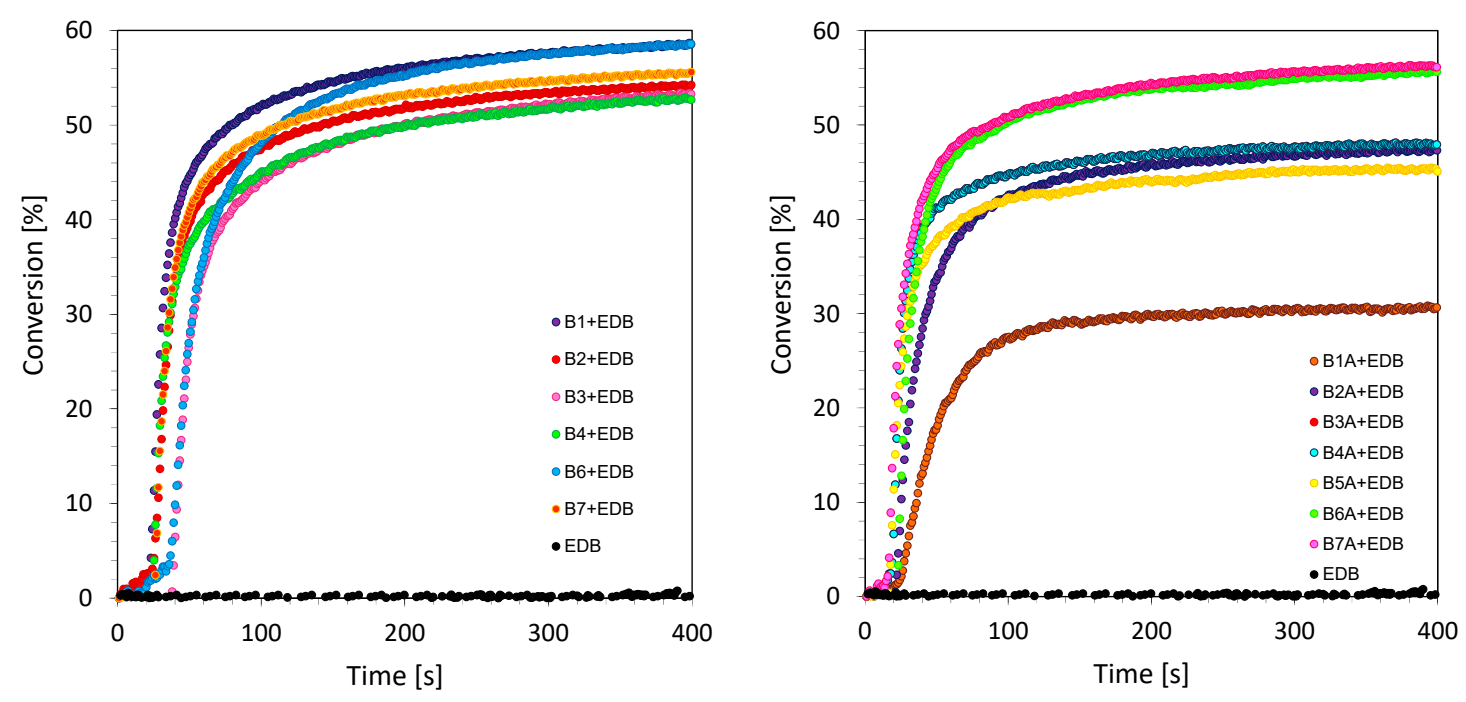

Figure 7. Photopolymerization profiles (double bond function conversion vs. irradiation time) in the presence of photoinitiating system based on biphenyls derivatives and EDB $(0.5 / 1.5 \% \mathrm{w} / \mathrm{w})$ at UV-A light LED source $365 \mathrm{~nm}$ for (a) 2-amino-4-methyl-6-(4-phenylphenyl)benzene-1,3-dicarbonitrile derivatives (series 1) and (b) 2-amino-4-methyl-6-phenyl-benzene-1,3-dicarbonitrile derivatives (series 2). 
Table 2 shows the conversion values obtained during the polymerization of various monomers according to different mechanisms and different light sources.

\subsection{Photoinduced Electron Transfer Process with Photo-Oxidation Mechanism Between Biphenyl Derivatives} and Iodonium Salt

As shown above, all investigated derivatives of 2-amino-4-methyl-6-phenyl-benzene1,3-dicarbonitrile derivatives can be employed as visible light photosensitizers in cationic and free-radical photoinitiated polymerizations. These derivatives initiate a photoinduced electron transfer reaction in the photoexcited state through oxidative processes in conjunction with iodonium salt (e.g., Speedcure 938). In this process, a bimolecular system is involved, in which one molecule, after absorbing the light, becomes an electron donor and is oxidized as a result of electron transfer, while the second molecule is reduced. In this case, the investigated 2-amino-4-methyl-6-phenyl-benzene-1,3-dicarbonitrile derivatives are the photosensitizers which, due to their spectroscopic properties (high molar extinction coefficient for the absorption band in the range of 300-425 nm), can easily absorb light in the UV-A and visible ranges and are easily oxidizable. Diaryliodonium salt (e.g., Speedcure 938) shows strong electron-acceptor properties in its basic state and is reduced as a result of electron transfer. The radicals resulting from the reduction of iodonium cation decay into secondary radicals are capable of further reaction, including initiation of a free-radical photopolymerization process, while the radicals produced from the oxidation of the biphenyl derivatives, in combination with anions from iodonium salts, may decay into strong protonic acids capable of initiating cationic polymerization. Alternatively, they may initiate the process directly. In order to demonstrate further that the 2-amino-4-methyl-6-phenyl-benzene-1,3-dicarbonitrile derivatives are suitable for the role of photosensitizers, their oxidation potential was determined by cyclic voltammetry (Figure 8a). The results summarized in Table 3 show that these compounds have sufficiently low oxidation potentials to interact effectively with iodonium salt. Additionally, an important parameter determining the efficiency of molecules in the photoinitiating system operating according to the photo-oxidation mechanism is the free energy change of electron transfer ( $\Delta \mathrm{Get})$ between individual components of the photoinitiating system. This process must be thermodynamically allowed; therefore, the free energy change ( $\Delta$ Get) must have a negative value. For this reason, the values of the parameter $(\Delta \mathrm{Get})$ from the classical Rehm-Weller equation were calculated. The singlet state energy of sensitizer $\left(E_{S 1}\right)$ was determined based on excitation and emission spectra (Figure $8 b$ ). In turn, triplet state energy $\left(\mathrm{E}_{\mathrm{T} 1}\right)$ was calculated from molecular orbital calculations using the density functional theory (DFT) method at a B3LYP/6-31G (d, p) level of theory (contour plots of HOMOs and LUMOs for all biphenyl derivatives structures were optimized by B3LYP/6-31G $(d, p)$ level of theory found in the Supporting Information in the Table S1). Negative values of Gibbs free energy were obtained for both singlet and triplet excited states, which confirmed the ability of electron exchange between the 2-amino-4-methyl-6-phenyl-benzene-1,3-dicarbonitrile derivatives and iodonium salt. Thereby, iodonium salt, in combination with a biphenyl compound, can act as an effective bimolecular photoinitiating system for cationic and free-radical photopolymerizations during a photoinduced electron transfer process under a photo-oxidation mechanism.

Additionally, in order to fully confirm this mechanism, the steady-state photolysis of derivatives in the presence of iodonium salt (Speedcure 938) was carried out. The interaction of 2-amino-4-methyl-6-phenyl-benzene-1,3-dicarbonitrile derivatives with Speedcure 938 was confirmed by the rapid decrease of intensity at the maximum of absorption $\left(\lambda_{\text {max-ab }}\right)$ spectra of the studied biphenyl derivatives over time. A very fast decrease in the absorption spectrum at a wavelength in the range $320-400 \mathrm{~nm}$ was observed, together with a noticeable increase in the absorption peak in the long-term spectrum in the range of about $400-500 \mathrm{~nm}$, which indicates the appearance of products of photolysis decay (example of photolysis can be found in the Supporting Information, Figures S99-S102). 


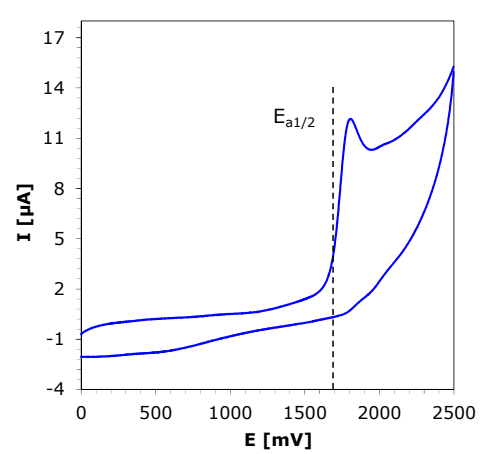

(a)

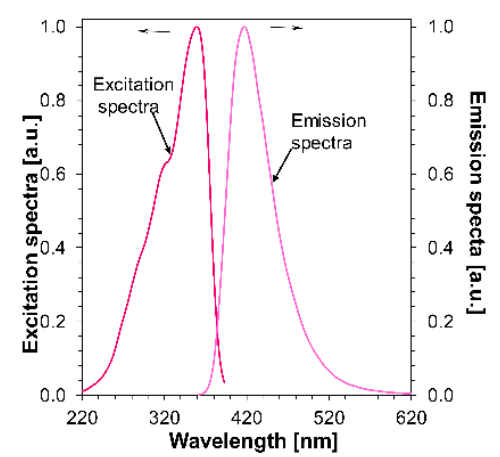

(b)

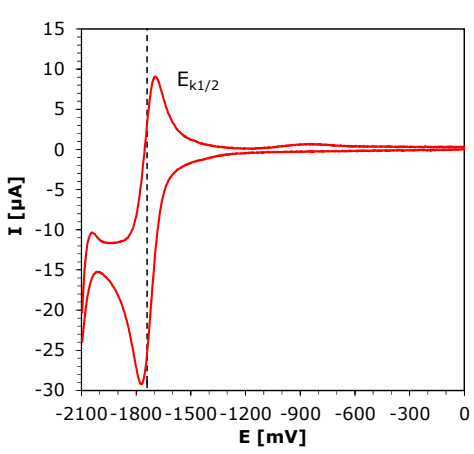

(c)

Figure 8. (a) Cyclic voltammetry for oxidation process $\left(\mathrm{CV}_{\mathrm{ox}}, \mathrm{vs}\right.$. $\left.\mathrm{Ag} / \mathrm{AgCl}\right)$ experiments in $\mathrm{ACN}$ (containing $0.1 \mathrm{M}$ tetrabutylammonium hexafluorophosphate) for the B2. (b) Absorption and fluorescence spectra for the determination of the excited singlet state energy for B2 derivatives. (c) Cyclic voltammetry for reduction process $\left(\mathrm{CV}_{\text {red }}\right.$, potential vs. $\left.\mathrm{Ag} / \mathrm{AgCl}\right)$ experiments in $\mathrm{ACN}$ (containing $0.1 \mathrm{M}$ tetrabutylammonium hexafluorophosphate) for the B2.

Moreover, the reactivity of the proposed bimolecular photoinitiating systems was also determined by the measurement of fluorescence quenching experiments. The intensity of the fluorescence spectrum of 2-amino-4-methyl-6-phenyl-benzene-1,3-dicarbonitrile derivatives was significantly reduced, as the amount of quencher (Speedcure 938) added to the solution of derivatives was increased. A linear correlation between the increase in added iodonium salt and the decrease in the intensity of fluorescence was demonstrated. On this basis, the Stern-Volmer coefficients $\left(\mathrm{K}_{\mathrm{SV}}\right)$ were determined (fluorescence quenching experiments for all biphenyl derivatives are found in the Supporting Information, Figures S43-S98). Fluorescence quenching experiments also provided information about the reaction constant $\left(\mathrm{k}_{\mathrm{q}}\right)$ between diaryliodonium salt and an excited singlet state of the biphenyl compound. The electron transfer rate constant $\mathrm{k}_{\mathrm{q}}$ between 2-amino-4-methyl-6-phenyl-benzene-1,3-dicarbonitrile derivatives and Speedcure 938 were extracted from the classical Stern-Volmer Equation (1) [49]:

$$
\frac{I_{0}}{I}=1+K_{S V}[\text { iodonium salt }]=1+k_{q} \tau_{0}[\text { iodonium salt }]
$$

where $\mathrm{I}_{0}$ and I stand for the fluorescence intensity of photosensitizer in the absence and presence of iodonium salt as a quencher, respectively, and $\tau_{0}$ stands for the lifetime of the excited state of the biphenyl photosensitizer in the absence of Speedcure 938 as a quencher.

The obtained coefficients $\left(\mathrm{K}_{\mathrm{SV}}\right)$ enabled the calculation of quantum efficiency of the electron transfer from the excited singlet state $\left(\Phi_{\mathrm{et}}(\mathrm{S} 1)\right)$ in the process of photo-oxidation [50] according to the equation below:

$$
\Phi_{e t(S 1)}=\frac{K_{S V}[\text { iodonium salt }]}{1+K_{S V}[\text { iodonium salt }]}
$$

Furthermore, in order to fully characterize the photo-oxidation process, an electron transfer rate constant $\mathrm{k}_{\mathrm{q}}$ was determined using the following relation:

$$
K_{S V}=k_{q} \tau_{0}
$$

where $\tau_{0}$ is the lifetime of the excited state of tested derivatives without the addition of iodonium salt. All calculated or measured values related to the process of photoinduced electron transfer via the photo-oxidation mechanism are presented in Table 3. From the data presented in this table, it is seen that the rate of dynamic quenching of the excited singlet state of photosensitizer slightly depends on the type of structure of the biphenyl derivatives. 
Table 3. Electrochemical and thermodynamically properties of investigated 2-amino-4-methyl6-phenyl-benzene-1,3-dicarbonitrile derivatives in terms of their use in photo-oxidation mechanism in light induces electron transfer process.

\begin{tabular}{|c|c|c|c|c|c|c|c|c|c|c|}
\hline & 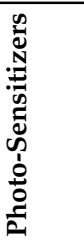 & $\begin{array}{c}\mathrm{E}_{\text {ox vs. }} \mathrm{Ag} / \mathrm{AgCl} \\
{[\mathrm{mV}]}\end{array}$ & $\begin{array}{c}\mathrm{E}_{\mathrm{S} 1} \\
{[\mathrm{eV}]}\end{array}$ & $\underset{[\mathrm{eV}]}{\Delta \mathrm{G}_{\mathrm{et}(\mathrm{S} 1)}{ }^{\mathrm{a}}}$ & $\begin{array}{c}\mathrm{E}_{\mathrm{T} 1} \\
{[\mathrm{eV}]}\end{array}$ & $\underset{[\mathrm{eV}]}{\Delta \mathrm{G}_{\mathrm{et}(\mathrm{T} 1)}{ }^{\mathrm{a}}}$ & $\begin{array}{l}\tau_{(\mathrm{S} 1)} \\
{[\mathrm{ns}]}\end{array}$ & $\begin{array}{c}\mathbf{K}_{\mathrm{sv}} \\
{\left[\mathbf{M}^{-1}\right]}\end{array}$ & $k_{q}\left[M^{-1} s^{-1}\right]$ & $\Phi_{\text {et (S1) }}$ \\
\hline \multirow{7}{*}{. } & B1 & 1815 & 3.22 & -0.77 & 2.65 & -0.19 & 2.775 & 32.158 & $1.16 \times 10^{10}$ & 0.40 \\
\hline & B2 & 1760 & 3.23 & -0.83 & 2.63 & -0.23 & 3.056 & 42.216 & $1.38 \times 10^{10}$ & 0.47 \\
\hline & B3 & 1595 & 3.21 & -0.98 & 2.60 & -0.36 & 2.605 & 30.413 & $1.17 \times 10^{10}$ & 0.39 \\
\hline & B4 & 1755 & 3.2 & -0.80 & 2.63 & -0.23 & 3.359 & 48.857 & $1.45 \times 10^{10}$ & 0.51 \\
\hline & B5 & 1818 & 3.2 & -0.74 & 2.66 & -0.20 & 3.086 & 32.872 & $1.07 \times 10^{10}$ & 0.41 \\
\hline & B6 & 1453 & 3.13 & -1.04 & 2.59 & -0.50 & 2.735 & 59.631 & $2.18 \times 10^{10}$ & 0.56 \\
\hline & B7 & 1751 & 3.21 & -0.82 & 2.66 & -0.27 & 3.244 & 46.945 & $1.45 \times 10^{10}$ & 0.50 \\
\hline \multirow{7}{*}{ 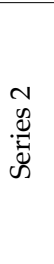 } & B1A & 1728 & 3.27 & -0.91 & 2.77 & -0.40 & 2.739 & 51.206 & $1.87 \cdot \times 10^{10}$ & 0.52 \\
\hline & B2A & 1763 & 3.27 & -0.87 & 2.75 & -0.35 & 2.944 & 36.995 & $1.26 \cdot \times 10^{10}$ & 0.44 \\
\hline & B3A & 1743 & 3.28 & -0.89 & 2.71 & -0.33 & 2.712 & 41.413 & $1.53 \cdot \times 10^{10}$ & 0.47 \\
\hline & B4A & 1355 & 3.13 & -1.14 & 2.66 & -0.66 & 3.436 & 28.668 & $8.84 \times 10^{9}$ & 0.38 \\
\hline & B5A & 1780 & 3.15 & -0.73 & 2.71 & -0.29 & 3.701 & 34.327 & $9.28 \times 10^{9}$ & 0.42 \\
\hline & B6A & 901 & 3.23 & -1.69 & 2.65 & -1.11 & 2.130 & 32.152 & $1.51 \cdot \times 10^{10}$ & 0.40 \\
\hline & B7A & 1828 & 3.2 & -0.57 & 2.72 & -0.25 & 3.505 & 32.855 & $9.37 \times 10^{9}$ & 0.41 \\
\hline
\end{tabular}

${ }^{a}$ calculated from the classical Rehm-Weller equation: $\Delta \mathrm{G}_{\mathrm{et}}=\mathrm{F}\left[\mathrm{E}_{\mathrm{ox}}\left(\mathrm{D} / \mathrm{D}^{+}\right)-\mathrm{E}_{\text {red }}\left(\mathrm{A}^{-} / \mathrm{A}\right)\right]-\mathrm{E}_{00}-\mathrm{Ze}^{2} / \varepsilon \mathrm{a}$; $\mathrm{E}_{\mathrm{ox}}\left(\mathrm{D} / \mathrm{D}^{+}\right)$- the electrochemically determined oxidation potential of the electron donor; $\mathrm{E}_{\mathrm{red}}\left(\mathrm{A}^{-} / \mathrm{A}\right)$ - the electrochemically determined reduction potential of the electron acceptor, $-0.64 \mathrm{~V}$ for the diaryliodonium salt (vs. $\mathrm{Ag} / \mathrm{AgCl}$ ) [51,52]; $\mathrm{E}_{\mathrm{S} 1}$ - singlet state energy of sensitizer determined based on excitation and emission spectra; $\mathrm{Ze}^{2} / \varepsilon \mathrm{a}$-interaction energy for the initially formed ion pair, negligible in polar solvents; $\mathrm{E}_{\mathrm{T} 1}$ - triplet state energy calculated from molecular orbital calculations (uB3LYP/6-31G* level of theory), $\Phi_{\mathrm{et}}=\mathrm{K}_{\mathrm{SV}}[\operatorname{Iod}] /\left(1+\mathrm{K}_{\mathrm{SV}}[\operatorname{Iod}]\right)$ with concentration of iodonium salt $[$ Iod $]=0.021 \mathrm{~mol} / \mathrm{dm}^{3}$.

This clearly demonstrates the usefulness of biphenyl derivatives as an interesting scaffold for new high-performance photosensitizers of iodonium salt on near-UV and visible regions for the photoinitiation of both epoxides (e.g., CADE monomer), glycidyl ethers (e.g., DEGDBA) and, significantly, acrylic monomers.

\subsection{Photoinduced Electron Transfer Process with Photo-Reduction Mechanism Between Biphenyl Derivatives and Amine}

The second mechanism that enables the initiation of the polymerization processes is photo-reduction, which is based on the transfer of electrons from the amine to the excited molecule of another compound, in this case, the 2-amino-4-methyl-6-phenyl-benzene-1,3-dicarbonitrile derivatives. In order to verify the potential application of derivatives in this type of process, research (as described above) was carried out. Calculations of Gibbs free energy confirmed the possibility of electron exchange for the singlet state. For the triplet state, only a few derivatives from series 2 are thermodynamically favorable. For others, the value $\Delta \mathrm{G}_{\mathrm{et}}$ is positive, which makes the process thermodynamically forbidden. For all proposed 2-amino-4-methyl-6-phenyl-benzene-1,3-dicarbonitrile derivatives, steady-state photolysis experiments were carried out in the presence of amine (EDB). This study proved that the proposed derivatives react quite slowly with amine, which is related to the slow electron transfer process, but can thus create effective systems initiating photopolymerization processes. All calculated or measured values related to the process of photoinduced electron transfer via the photo-reduction mechanism are presented in Table 4. 
Table 4. Electrochemical and thermodynamic properties of investigated 2-amino-4-methyl6-phenyl-benzene-1,3-dicarbonitrile derivatives in terms of their use in photo-reduction mechanism in light induces electron transfer process.

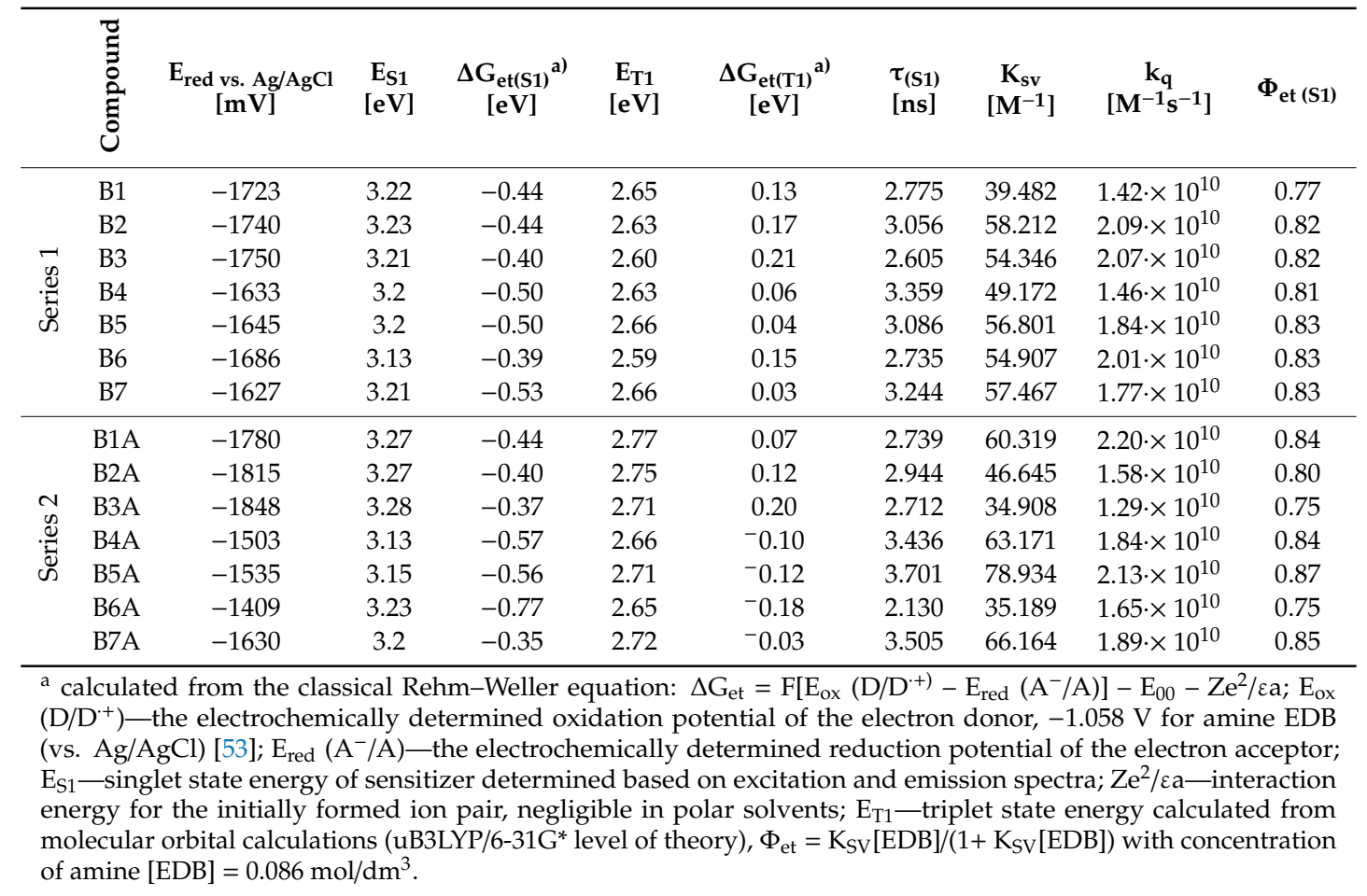

Examples of the reduction curve for the B2 compound are shown in Figure 8c. As was proven in real-time FT-IR photopolymerization research, the proposed 2-amino-4-methyl-6-phenylbenzene-1,3-dicarbonitrile derivatives can be successfully used in bimolecular photoinitiating systems for photopolymerization processes, according to both photo-oxidation and photo-reduction mechanisms. For additional confirmation of the usefulness of the proposed compounds as high-performance photosensitizers, a number of photopolymerization processes were carried out in the previous section. For example, in order to prove with certainty the mechanism of photo-reduction, free-radical photopolymerization of acrylate monomer (TMPTA) was performed with the participation of a two-component system based on amine and biphenyl derivatives (Figure 7).

2.7. Performance of the Bimolecular Photoinitiating System Based on 2-Amino-4-Methyl-6-PhenylBenzene-1,3-Dicarbonitrile Derivatives and Iodonium Salt for Obtaining Different Types of Interpenetrating Polymer Networks

It is well known that to overcome the limitations of acrylate and epoxy photopolymerization, these systems can be mixed together in order to obtain interpenetrating polymer networks (IPNs). In this approach, the interpenetrating polymer networks (IPNs) are polymers consisting of at least two monomers, each reacting according to a different mechanism. By using different monomers in a single process, synergism is expected in the final product. Therefore, we analyzed the different types of compositions during the simultaneous acrylate and epoxide polymerizations (Table 5).

Moreover, we also examined the effect of adding hybrid monomer to the process of forming IPNs networks. Hybrid copolymerization of two or more structurally different monomers (e.g., cyclic epoxide and acrylate or methacrylate-type monomers) is very interesting, as new copolymers can be created. However, hybrid photo-copolymerization is a challenge, because the reactivity and polymerization mechanism of unlike monomers are extremely different. Here, we report interesting hybrid copolymerization via the hybrid monomer 3,4-epoxycyclohexylmethyl methacrylate (Cyclomer M100) containing the epoxycyclohexyl group polymerizable exclusively by cationic 
polymerization mechanism, and another one-the methacrylate group, polymerized exclusively by free-radical polymerization. It is known that methacrylate monomers do not polymerize by cationic photopolymerization mechanism, while epoxy monomers do not polymerize by free-radical means. Nevertheless, when bimolecular photoinitiating systems, which can photoinitiate cationic as well as free-radical photopolymerization, were applied, we observed the formation of linear poly(methacrylate) chains from M100 monomer. On the other hand, when cycloaliphatic epoxide monomer was applied, cross-linked polyether-type polymer chains were formed from CADE and M100 monomers.

In this section, a combination of different monomers was investigated in order to eliminate single reaction defects and to obtain a product with the desired properties (e.g., high resolution of printing patterns) and high conversions of monomers. For these studies, two component initiating systems were selected: B6/Iod $(0.1 / 1 \% \mathrm{w} / \mathrm{w})$ and $\mathrm{B} 6 \mathrm{~A} / \mathrm{Iod}(0.1 / 1 \% \mathrm{w} / \mathrm{w})$. The reason for choosing 2-amino-4-[4-(4-methylsulfanylphenyl)-phenyl]-6-methyl-benzene-1,3-dicarbonitrile (B6) and 2-amino-4-methyl-6-(4-methylsulfanylphenyl)-benzene-1,3-dicarbonitrile (B6A) is the fact that they have the lowest values of Gibbs free energy, which was calculated using the Rehm-Weller equation. Additionally, their exceptional abilities as co-initiators in the processes of photoinduced polymerization via the photo-oxidation mechanism were confirmed by the highest conversion values of the previously analyzed monomers. For comparison, the tests were carried out both under laminate conditions and in air for complete characterization of the analyzed systems. All obtained conversions are summarized in Table 5.

The following compositions were analyzed using real-time FITR: CADE/TMPTA, CADE/M100, and TMPTA/M100, for which cationic and radical photopolymerization processes of individual monomers were studied in detail and described in the previous sections. In all cases, the systems consisted of sections reacting by breaking double bonds at wavelengths of $1635 \mathrm{~cm}^{-1}$, or by the opening of oxirane rings at $790 \mathrm{~cm}^{-1}$. The best values of conversions were obtained for the CADE/TMPTA system. It was clearly evidenced that the photopolymerization of the acrylate monomer and epoxide monomer occurred on similar time scales but independently from each other. Moreover, the acrylate monomer was found to polymerize faster and more extensively than the epoxide one. The use of epoxy monomers allowed the partial reduction of oxygen inhibition of free-radical photopolymerization. Nevertheless, oxygen inhibition could not be completely eliminated by using only a high viscosity cycloaliphatic epoxide monomer. Therefore, we investigated the influence of the thiol monomer addition to the photopolymerizable compositions on the value of achieved monomer conversion, especially methacrylate monomer, as well as on resolution of the printing patterns. Thiol-en photopolymerization is a conventional free-radical polymerization of multifunctional thiol and variety of unsaturated functional groups, such as maleimides, acrylates, and norbornenes. First, radical species, which are produced during photolysis from photoinitiator, subsequently abstract a hydrogen from the thiol monomer to create a thiyl radical. Secondly, the thiyl radical adds across the carbon-carbon double bond, resulting in the formation of a carbon-centered radical. The process of propagation occurs rapidly and to high conversions. Moreover, the termination occurs as a result of radical coupling, which can occur between thiols or carbon-centered radicals. A significant advantage of thiol-en processes over traditional free-radical polymerizations is lack of oxygen inhibition. This is a crucial property for the application of compositions with thiol monomers. Additionally, the use of thiol as one of the elements of the composition eliminates the oxygen inhibition of other monomers, thus ensuring their higher conversions. Comparing the following combinations-CADE/TMPTA, CADE/TMPTA/TMPMP, and TMPTA/TMPMP-the above-mentioned trend is strongly noticeable in the obtained values of conversions. The photopolymerization processes were controlled by the disappearance of IR absorption vibration bands at the number of wavelengths: $1635 \mathrm{~cm}^{-1}$, which is responsible for the double bond content; $790 \mathrm{~cm}^{-1}$, which is related to the epoxy group; and $2575 \mathrm{~cm}^{-1}$, which corresponds to the $\mathrm{SH}$ bond. The probable conversion of monomers was calculated individually for each monomer in the investigated composition. The final conversions related to the reactive group/bonds are given in Table 5. According to the theory, the addition of thiol enables the acquisition of high conversion values 
for acrylic monomers through the elimination of negative oxygen influence. The addition of thiol, however, does not influence the process of the cationic polymerization of the epoxy monomer.

For the photopolymerization process of every composition, the influence of the type of the measurement condition is clearly visible, as significant differences in the final conversion values were observed. In the case of the laminate condition, higher values of conversion were obtained for processes involving a free-radical mechanism. On the other hand, while carrying out the measurements in air, an influence of the oxygen on the conversion of double bond of the methacrylate group was noticed.

Table 5. Summary of functional group conversions of used monomers, using photoinitiating system based on bis-(4-t-butylphenyl)iodonium hexafluorophosphate (Speedcure $938 \mathrm{wt} 1 \%$ ) and 2-amino-4-methyl-6-phenyl-benzene-1,3-dicarbonitrile derivatives.

\begin{tabular}{|c|c|c|c|c|c|}
\hline \multicolumn{6}{|c|}{ CONDITION: IN LAMINATE } \\
\hline \multirow[t]{2}{*}{ Composition } & \multirow[t]{2}{*}{ Conversion $[\%]$} & \multicolumn{2}{|c|}{$\begin{array}{c}\text { B6/Iod } \\
(0.1 / 1 \% \mathrm{w} / \mathrm{w})\end{array}$} & \multicolumn{2}{|c|}{$\begin{array}{c}\text { B6A/Iod } \\
(0.1 / 1 \% \mathrm{w} / \mathrm{w})\end{array}$} \\
\hline & & $@ 365$ nm & $@ 405$ nm & $@ 365$ nm & @405 nm \\
\hline \multirow{2}{*}{$\begin{array}{l}\text { CADE/TMPTA } \\
(50 / 50 \% \mathrm{w} / \mathrm{w})\end{array}$} & EPOX at $790 \mathrm{~cm}^{-1}$ & 37.9 & 45.4 & 46.5 & 19.9 \\
\hline & ACRYLATE at $1635 \mathrm{~cm}^{-1}$ & 75.2 & 76.4 & 77.0 & 74.5 \\
\hline \multirow{3}{*}{$\begin{array}{l}\text { CADE/TMPTA/THIOL } \\
(40 / 40 / 20 \% \mathrm{w} / \mathrm{w} / \mathrm{w})\end{array}$} & EPOX at $790 \mathrm{~cm}^{-1}$ & 44.7 & 42.5 & 40.6 & 47.7 \\
\hline & ACRYLATE at $1635 \mathrm{~cm}^{-1}$ & 97.9 & 90.8 & 97.2 & 97.5 \\
\hline & THIOL at $2575 \mathrm{~cm}^{-1}$ & 90.8 & 96.6 & 43.2 & 38.4 \\
\hline \multirow{2}{*}{$\begin{array}{l}\text { TMPTA/THIOL } \\
(50 / 50 \% \mathrm{w} / \mathrm{w})\end{array}$} & THIOL at $2575 \mathrm{~cm}^{-1}$ & 41.2 & 50.2 & 37.0 & 36.1 \\
\hline & ACRYLATE at $1635 \mathrm{~cm}^{-1}$ & 99.6 & 98.7 & 99.7 & 99.6 \\
\hline \multirow{2}{*}{$\begin{array}{l}\text { CADE/M100 } \\
(50 / 50 \% \mathrm{w} / \mathrm{w})\end{array}$} & EPOX at $790 \mathrm{~cm}^{-1}$ & 33.3 & 22.3 & 28.9 & 32.8 \\
\hline & $\begin{array}{l}\text { METHACRYLATE } \\
\text { at } 1635 \mathrm{~cm}^{-1}\end{array}$ & 95.3 & 91.7 & 91.2 & 94.0 \\
\hline \multirow{2}{*}{$\begin{array}{l}\text { TMPTA/M100 } \\
(50 / 50 \% \mathrm{w} / \mathrm{w})\end{array}$} & EPOX at $790 \mathrm{~cm}^{-1}$ & 33.7 & 29.2 & 38.4 & 35.0 \\
\hline & $\begin{array}{c}\text { (METH)ACRYLATE } \\
\text { at } 1635 \mathrm{~cm}^{-1}\end{array}$ & 58.2 & NP & 62.1 & 59.0 \\
\hline \multirow{2}{*}{$\begin{array}{l}\text { CADE/TEGDVE } \\
(50 / 50 \% \mathrm{w} / \mathrm{w})\end{array}$} & EPOX at $790 \mathrm{~cm}^{-1}$ & 33.7 & 29.2 & 17.5 & 20.0 \\
\hline & VINYL at $1620 \mathrm{~cm}^{-1}$ & 66.9 & 62.3 & 58.2 & 61.4 \\
\hline \multicolumn{6}{|c|}{ CONDITION: IN THE AIR } \\
\hline \multirow[t]{2}{*}{ Composition } & \multirow[t]{2}{*}{ Conversion $[\%]$} & \multicolumn{2}{|c|}{$\begin{array}{c}\text { B6/Iod } \\
(0.1 / 1 \% \mathrm{w} / \mathrm{w})\end{array}$} & \multicolumn{2}{|c|}{$\begin{array}{c}\text { B6A/Iod } \\
(0.1 / 1 \% \mathrm{w} / \mathrm{w}) \\
\end{array}$} \\
\hline & & $@ 365$ nm & $@ 405$ nm & $@ 365$ nm & @405 nm \\
\hline \multirow{2}{*}{$\begin{array}{l}\text { CADE/TMPTA } \\
(50 / 50 \% \mathrm{w} / \mathrm{w})\end{array}$} & EPOX at $790 \mathrm{~cm}^{-1}$ & 58.1 & 56.8 & 53.0 & 51.6 \\
\hline & ACRYLATE at $1635 \mathrm{~cm}^{-1}$ & 29.9 & 23.9 & 34.6 & 23.4 \\
\hline \multirow{3}{*}{$\begin{array}{l}\text { CADE/TMPTA/THIOL } \\
(40 / 40 / 20 \% \mathrm{w} / \mathrm{w} / \mathrm{w})\end{array}$} & EPOX at $790 \mathrm{~cm}^{-1}$ & 45.5 & 52.6 & 46.2 & 41.7 \\
\hline & ACRYLATE at $1635 \mathrm{~cm}^{-1}$ & 86.6 & 84.2 & 81.7 & 79.2 \\
\hline & THIOL at $2575 \mathrm{~cm}^{-1}$ & 84.5 & 88.0 & 81.2 & 78.4 \\
\hline \multirow{2}{*}{$\begin{array}{l}\text { TMPTA/THIOL } \\
(50 / 50 \% \mathrm{w} / \mathrm{w})\end{array}$} & THIOL at $2575 \mathrm{~cm}^{-1}$ & 61.3 & 59.5 & 60.6 & 61.4 \\
\hline & ACRYLATE at $1635 \mathrm{~cm}^{-1}$ & 93.5 & 96.7 & 97.4 & 97.1 \\
\hline \multirow{2}{*}{$\begin{array}{l}\text { CADE/M100 } \\
(50 / 50 \% \mathrm{w} / \mathrm{w})\end{array}$} & EPOX at $790 \mathrm{~cm}^{-1}$ & 53.8 & 49.8 & 24.1 & 27.1 \\
\hline & $\begin{array}{l}\text { METHACRYLATE } \\
\text { at } 1635 \mathrm{~cm}^{-1}\end{array}$ & 15.7 & 8.8 & 7.2 & NP \\
\hline \multirow{2}{*}{$\begin{array}{l}\text { TMPTA/M100 } \\
(50 / 50 \% \mathrm{w} / \mathrm{w})\end{array}$} & EPOX at $790 \mathrm{~cm}^{-1}$ & 67.1 & 62.0 & 73.3 & 69.2 \\
\hline & $\begin{array}{c}\text { (METH)ACRYLATE } \\
\text { at } 1635 \mathrm{~cm}^{-1}\end{array}$ & 56.2 & NP & 12.1 & 29.1 \\
\hline \multirow{2}{*}{$\begin{array}{l}\text { CADE/TEGDVE } \\
(50 / 50 \% \mathrm{w} / \mathrm{w})\end{array}$} & EPOX at $790 \mathrm{~cm}^{-1}$ & 993 & 95.6 & 72.2 & 33.0 \\
\hline & VINYL at $1620 \mathrm{~cm}^{-1}$ & 86.3 & 86.8 & 71.7 & 31.9 \\
\hline
\end{tabular}




\subsection{Resolution Test of IPN Systems with the Standard 1951 USAF}

In order for a given composition to be used in 3D printing, its printout must be characterized by the proper recognizability of details. One of the methods for determining optical resolution is to use the 1951 USAF resolution test chart. The different compositions tested in Section 3.7. were irradiated with LED @365 nm, 7.97 mW/ $\mathrm{cm}^{2}$ through the USAF mask for a period appropriate to the cross-linking of the exposed template. Then, by identifying the number of the group and the number of the element for which the individual details are most visible, resolution was determined using Equation (6), where group number is taken horizontally from the mask and the element numbers are represented by vertical numbers (see Figure 9).

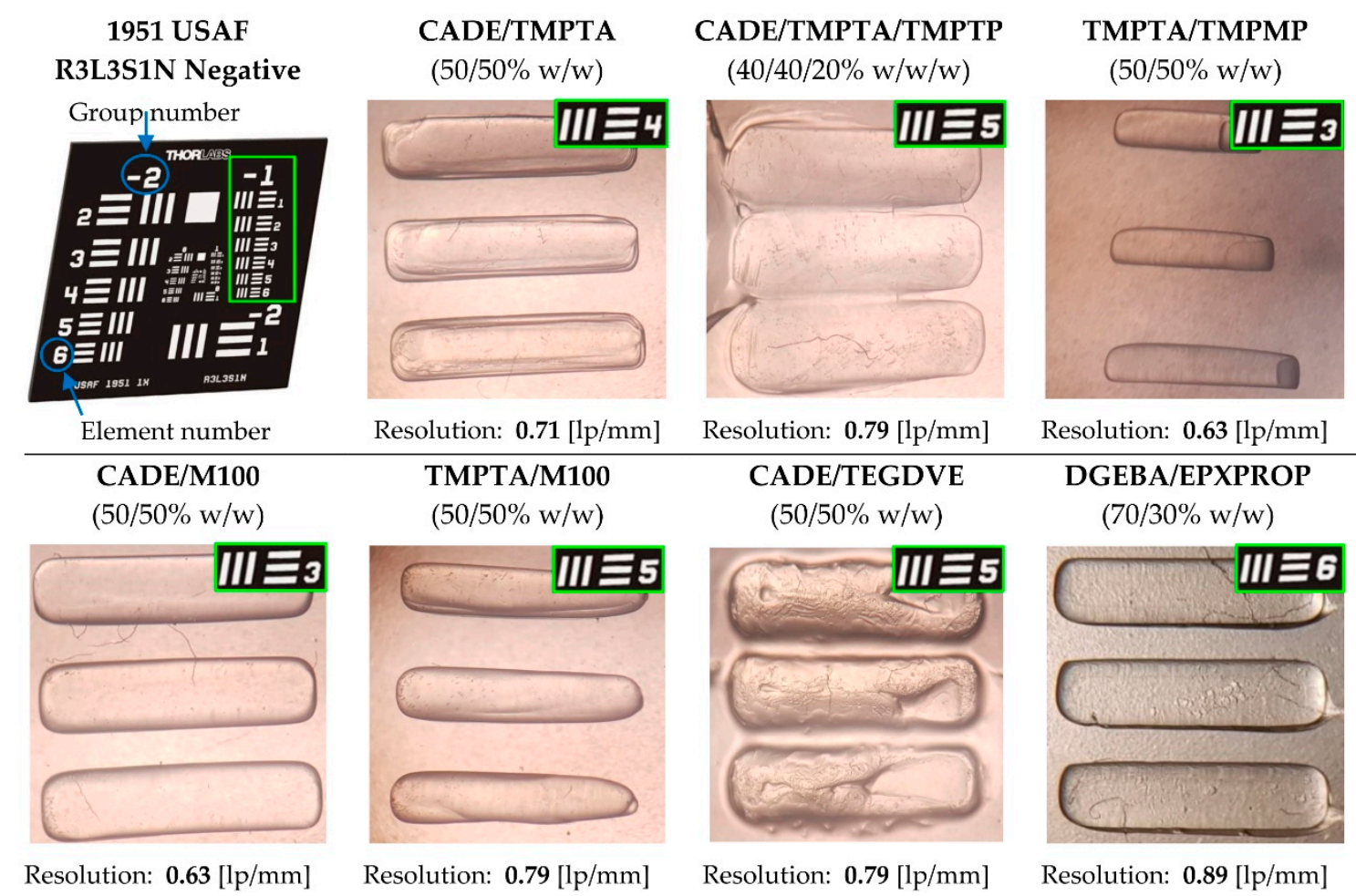

Figure 9. Determining optical resolution of printout of investigated compositions by imaging a USAF 1951 resolution test target. (The photo of the mask is from: https://www.thorlabs.com/newgrouppage9. cfm?objectgroup_id=4338).

For the resolution calculation, the best pattern for the composition (element number) was selected, while the single area (same group number) was always used for comparison purposes. The best printouts were obtained for compositions CADE/TMPTA (50/50\% w/w), CADE/M100 (50/50\% $\mathrm{w} / \mathrm{w} /)$, and DGEBA/EPXPROP $(70 / 30 \% \mathrm{w} / \mathrm{w})$. In the case of using thiol or a vinyl monomer, a significant deterioration in optical resolution is noticeable. This is a consequence of the high reactivity of these monomers in the proposed systems. Additionally, the use of vinyl monomers induces the polymerization process to occur even after the source of light is turned off, which results in polymerization of the entire sample, and not only of the exposed elements of the composition. Photographs of printouts after irradiation through the mask, together with the calculated resolution for individual compositions, are shown in Figure 9.

\subsection{D printing Experiments}

Bearing in mind the above research results, the new versatile bimolecular photoinitiating systems based on biphenyl derivatives and iodonium salt are efficient photoinitiators in initiated free-radical and cationic processes. A photopolymer experiment of $3 \mathrm{D}$ printing was carried out using all 
the compositions describe above. In the 3D printing experiment, the composition consisting of DGEBA/EPXPROP $(70 \% / 30 \% \mathrm{w} / \mathrm{w})$ in the presence of biphenyl derivatives/Iod $(0.2 / 2 \% \mathrm{w} / \mathrm{w})$ was selected, as the high photosensitivity of this resin allows for an efficient polymerization process in 3D. Thick samples up to $\sim 1000 \mu \mathrm{m}$ were easily obtained with a high resolution value $(0.89 \mathrm{~lm} / \mathrm{mm})$. The final results of the experiment are presented in Figure 10, which proves that the proposed compounds, when properly selected in terms of composition, can act as highly efficient for 3D photoprinting.

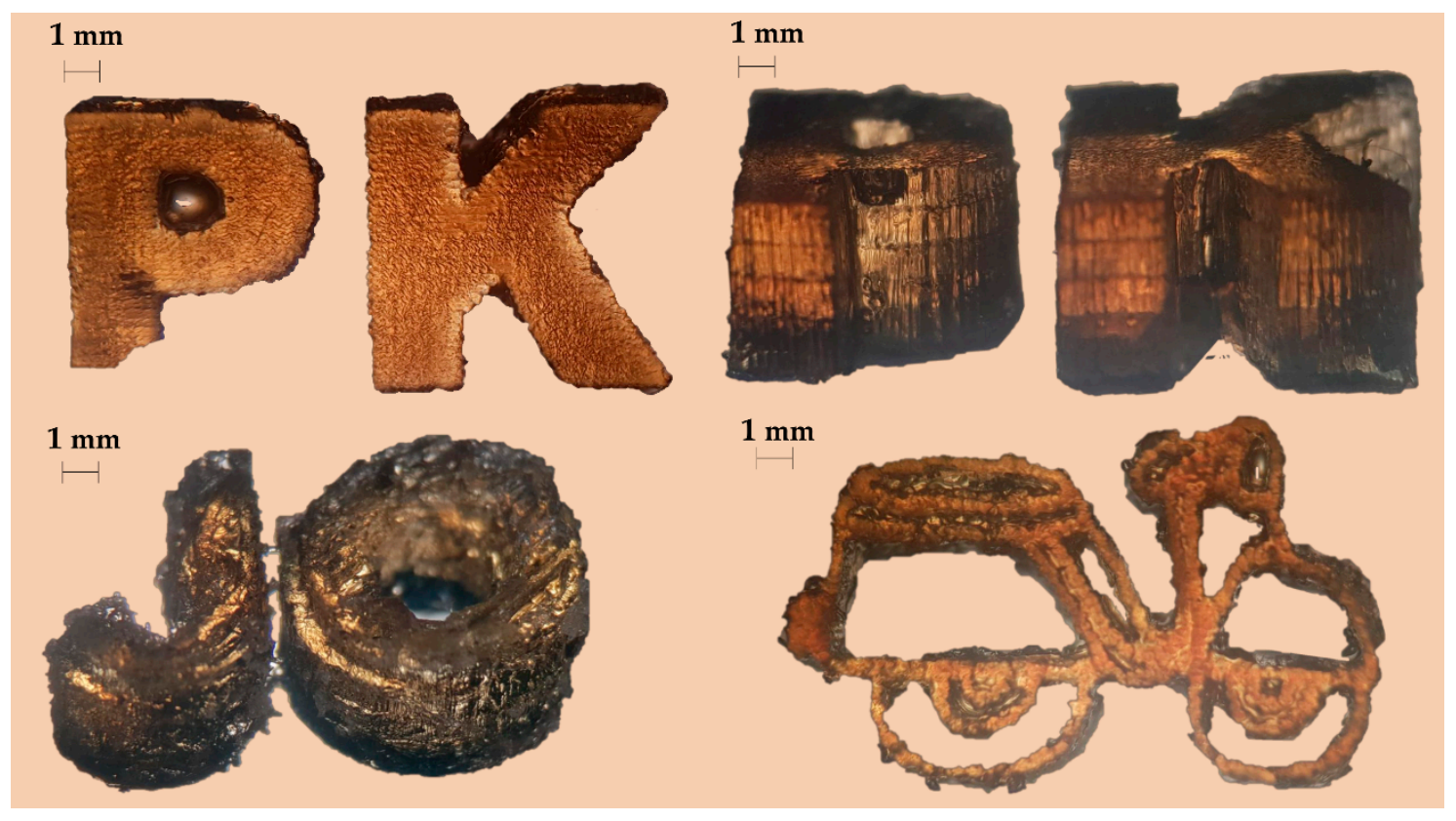

Figure 10. Cationic photopolymerization of glycidyles: DGEBA/EPXPROP $(70 \% / 30 \% \mathrm{w} / \mathrm{w})$ in the presence of biphenyls derivatives/Iod $(0.2 / 2 \% \mathrm{w} / \mathrm{w})$ for $3 \mathrm{D}$ printing.

\section{Experimantal}

\subsection{Materials}

The two series of 2-amino-4-methyl-6-phenyl-benzene-1,3-dicarbonitrile derivatives were investigated in the role of photosensitizers using various photopolymerization processes. Series 1 consisted of:

2-amino-4-methyl-6-(4-phenylphenyl)benzene-1,3-dicarbonitrile. (B1), 2-amino-4-[4-(4-methylphenyl) phenyl]-6-methyl-benzene-1,3-dicarbonitrile, (B2), 2-amino-4-[4-(4-methoxyphenyl)phenyl]-6-methylbenzene-1,3-dicarbonitrile (B3), 2-amino-4-[4-(4-cyanophenyl)phenyl]-6-methyl-benzene-1,3-dicarbonitrile (B4), 2-amino-4-[4-(4-methylsulfonylphenyl)phenyl]-6-methyl-benzene-1,3-dicarbonitrile (B5), 2-amino4-[4-(4-methylsulfanylphenyl)phenyl]-6-methyl-benzene-1,3-dicarbonitrile (B6), and 2-amino-4-methyl6-[4-[4-(trifluoromethyl)phenyl]phenyl]benzene-1,3-dicarbonitrile (B7).

The second series consisted of following compounds: 2-amino-4-methyl-6-phenyl-benzene1,3-dicarbonitrile (B1A), 2-amino-4-(4-methylphenyl)-6-methyl-benzene-1,3-dicarbonitrile (B2A), 2-amino-4-(4-methoxyphenyl)-6-methyl-benzene-1,3-dicarbonitrile (B3A), 2-amino-4-(4-cyanophenyl)6-methyl-benzene-1,3-dicarbonitrile (B4A), 2-amino-4-methyl-6-(4-methylsulfonylphenyl)benzene1,3-dicarbonitrile (B5A), 2-amino-4-methyl-6-(4-methylsulfanylphenyl)benzene-1,3-dicarbonitrile (B6A), and 2-amino-4-methyl-6-[4-(trifluoromethyl)phenyl]benzene-1,3- dicarbonitrile (B7A).

The studied details of synthesis and physicochemical data of the derivatives of 2-amino-4-methyl-6-phenyl-benzene-1,3-dicarbonitrile are given in the Supporting Information. The structures of the compounds are shown in Figure 11. 


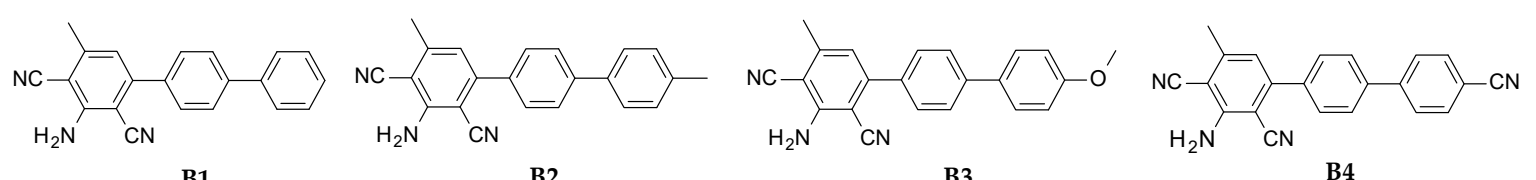<smiles>COS(=O)(=O)c1ccc(-c2ccc(-c3cc(C)c(C#N)c(N)c3C#N)cc2)cc1</smiles>

B3

B4<smiles>CSc1ccc(-c2ccc(-c3cc(C)c(C#N)c(N)c3C#N)cc2)cc1</smiles>

B6

B7<smiles>Cc1cc(-c2ccccc2)c(C#N)c(N)c1C#N</smiles>

B1A

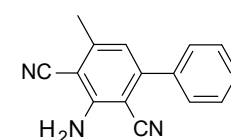

B2A

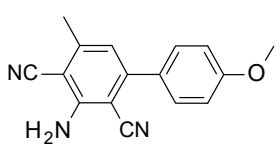

B3A

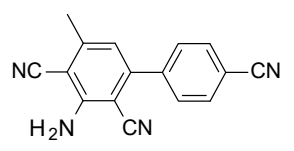

B4A<smiles>COc1ccc(-c2cc(C)c(C#N)c(N)c2C#N)cc1</smiles>

B5A

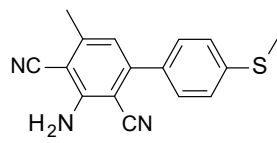

B6A

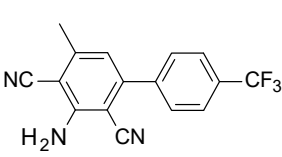

B7A

Figure 11. Structure of investigated 2-amino-4-methyl-6-phenyl-benzene-1,3-dicarbonitrile derivatives.

Bis-(4-t-butylphenyl)iodonium hexafluorophosphate (Speedcure 938, Lambson Ltd., Wetherby, UK) was used as commercial one-component cationic photoinitiator, and 2,4-diethyl-9H-thioxanthen-9-one (DETHX, from Sigma Aldrich) was applied as a commercial sensitizer, used for comparison. As a part of type II free-radical photoinitiators for the role of effective donor electron ethyl 4-(dimethylamino)benzoate (EDB, from Sigma Aldrich) was used. 3,4-epoxycyclohexylmethyl3,4-epoxycyclohexane-carboxylate (S105, Lambson Ltd., Wetherby, UK) and trimethylolpropane triacrylate (TMPTA, from Sigma Aldrich) were applied as model monomers for the cationic and free-radical photopolymerization processes, respectively.

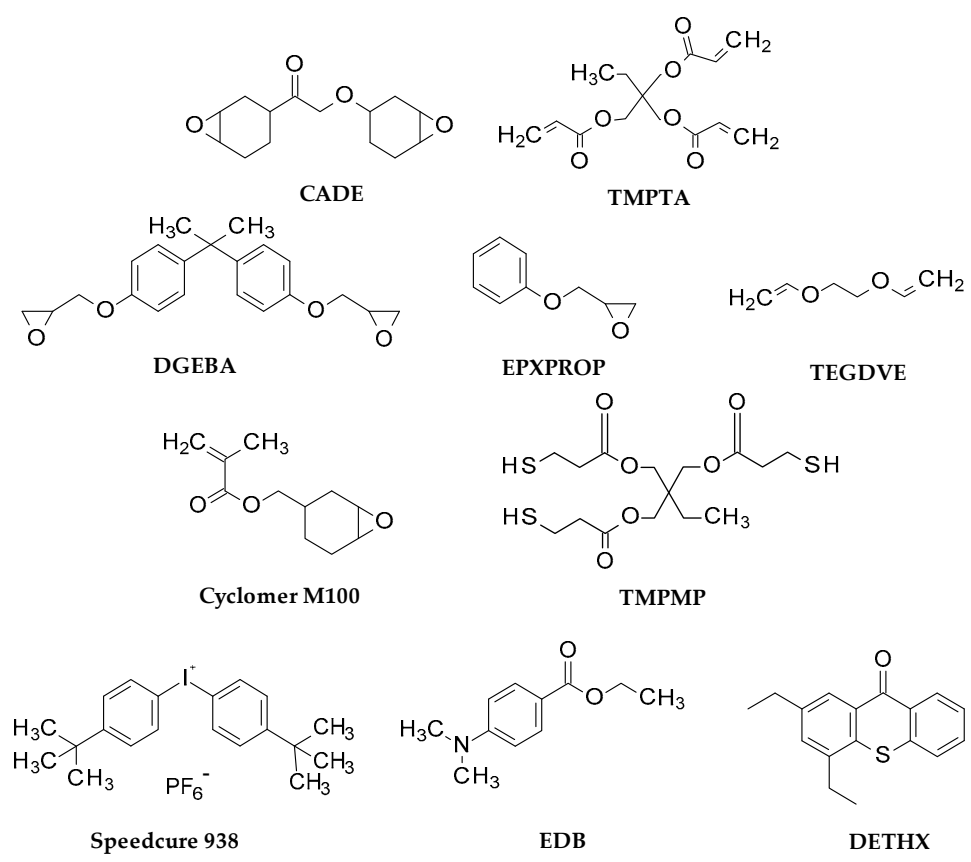

Figure 12. Structures of monomers and other used compounds.

For formation of various interpenetrating photopolymer networks, we used different type of monomers, as follows: 2,2-bis[4-(glycidyloxy)phenyl]propane (Bisphenol A diglycidyl ether-DGEBA, from Sigma Aldrich), 1,2-epoxy-3-phenoxypropane (EPXPROP, from Sigma Aldrich), 
3,4-epoxycyclohexylmethyl methacrylate (Cyclomer M100, from Daicel Corporation, Japan), triethylene glycol divinyl ether (TEGDVE, from Sigma Aldrich), and trimethylolpropane tris (3-mercaptopropionate) (TMPMP, from Sigma Aldrich). All used compounds are shown in Figure 12.

\subsection{Irradiation Sources}

The light source for the real-time FT-IR method was the $365 \mathrm{~nm}$ M365L2 UV-LED diode (0.7 A, $\mathrm{I}_{0}=3.77 \mathrm{~mW} / \mathrm{cm}^{2}$, from Thorlabs Inc., Tampa, FL, USA), the $365 \mathrm{~nm}$ M365LP1 UV-LED diode $\left(0.7 \mathrm{~A}, \mathrm{I}_{0}=\right.$ $9.37 \mathrm{~mW} / \mathrm{cm}^{2}$, from Thorlabs Inc., Tampa, FL, USA), and the $405 \mathrm{~nm} \mathrm{M} 405 \mathrm{LP} 1\left(0.7 \mathrm{~A}, \mathrm{I}_{0}=11,89 \mathrm{~mW} / \mathrm{cm}^{2}\right.$, from Thorlabs Inc., Tampa, FL, USA) powered by a DC2200 regulated power supply (from Thorlabs Inc., Tampa, FL, USA). The UV-LED was started $10 \mathrm{~s}$ after the start of spectral registration. The distance between irradiation sources and formulations was $2.1 \mathrm{~cm}$.

\subsection{Absorption and Fluorescence Characteristics}

The absorbance properties of the biphenyl derivatives were studied using a SilverNova TEC-X2 spectrometer (from StellarNet, Inc., Tampa, FL, USA) with the range of 190-1100 nm, which was equipped with a broadband UV/Vis deuterium-halogen light source SL5 (from StellarNet, Inc., Tampa, FL, USA) that covers the 190-2500 $\mathrm{nm}$ range. The SL5 lamp was connected via fiber optic cable to cuvette holders with a quartz cuvette with $1.0 \mathrm{~cm}$ optical path, with the return signal routed to the spectrometer via SMA 905 input connector. Next, the absorbance data were converted into extinction coefficients, expressed in classical units $\left[\mathrm{dm}^{3} \cdot \mathrm{mol}^{-1} \cdot \mathrm{cm}^{-1}\right]$.

Fluorescence measurements were carried out using the same miniature spectrometer. The spectral characteristics of the derivatives were measured in acetonitrile at room temperature $\left(25^{\circ} \mathrm{C}\right)$ using 10-mm-thick quartz cells. The extinction source of light was UV-LED-320 with $\lambda_{\max }=320 \mathrm{~nm}$ (UVTOP315-BL-TO39, Roithner Laser Technik GmbH, Wien, Austria).

\subsection{Electrochemical Characteristic Determination of Oxidation and Reduction Potential}

The oxidation and reduction potentials of the investigated 2-amino-4-methyl-6-phenylbenzene-1,3-dicarbonitrile derivatives $\left(\mathrm{E}_{\mathrm{ox}} \mathrm{vs} . \mathrm{Ag} / \mathrm{AgCl}\right)$ and the redox potentials $\left(\mathrm{E}_{\text {red }} \mathrm{vs} . \mathrm{Ag} / \mathrm{AgCl}\right)$ were measured in acetonitrile by cyclic voltammetry with tetrabutylammonium hexafluorophosphate $(0.1 \mathrm{M})$ (from Sigma Aldrich) as a supporting electrolyte (Electrochemical Analyzer M161 and the Electrode Stand M164, from MTM-ANKO, Cracow, Poland). The working electrode was a platinum disk and the reference was a silver chloride electrode- $\mathrm{Ag} / \mathrm{AgCl}$; a scan rate of $0.1 \mathrm{~V} / \mathrm{s}$ was used, ferrocene was used as a standard, and the potentials were determined from half peak potentials. The Gibbs free energy change Get for an electron transfer between the components of the bimolecular photoinitiating system was calculated using the classical Equation (4):

$$
\Delta G_{e t}=F\left[E_{o x}\left(D / D^{\bullet+}\right)-E_{r e d}\left(A^{\bullet-} / A\right)\right]-E_{00}-\left(Z e^{2} / \varepsilon a\right)
$$

where $\mathrm{E}_{\mathrm{Ox}}\left(\mathrm{D} / \mathrm{D}^{\bullet+}\right)$ is the oxidation potential of the electron donor, $\mathrm{E}_{\mathrm{red}}\left(\mathrm{A}^{\bullet-} / \mathrm{A}\right)$ the reduction potential of the electron acceptor, $\mathrm{E}_{00}$ the excited state energy, and $\left(\mathrm{Ze}^{2} / \varepsilon \mathrm{a}\right)$ the electrostatic interaction energy for the initially formed ion pair. Parameter $\left(\mathrm{Ze}^{2} / \varepsilon a\right)$ is generally considered negligible in polar solvents. The excited state energy was determined from the excitation and emission spectra using Quanta Master ${ }^{\mathrm{TM}} 40$ spectrofluorometer (from Photon Technology International (PTI), currently a part of Horiba) at varied excitation wavelengths in the range of $200-800 \mathrm{~nm}$.

\subsection{Steady-State Photolysis}

During the measurements, cuvettes with appropriate 2-amino-4-methyl-6-phenyl- benzene-1,3dicarbonitrile derivatives in acetonitrile were irradiated by the UV-LED-365 M365L2 (from Thorlabs Inc., Tampa, FL, USA) emitting light with the wavelength at $\lambda_{\max }=365 \mathrm{~nm}\left(\sim 190 \mathrm{~mW} / \mathrm{cm}^{2}\right.$, current $700 \mathrm{~mA}$ ) in the time of $30 \mathrm{~min}$. The photolysis of biphenyls derivatives in the presence of Speedcure 
$938\left(2.7 \cdot \times 10^{-2} \mathrm{~mol} / \mathrm{dm}^{3}\right)$ or EDB $\left(4.3 \cdot \times 10^{-3} \mathrm{~mol} / \mathrm{dm}^{3}\right)$ were determined with the same parameters in the time of $10 \mathrm{~min}$. The source of light was powered by a DC2200-regulated power supply (from Thorlabs Inc., Tampa, FL, USA). The UV-Vis spectra was recorded with the UV/Vis deuterium-halogen light source SL5 (from StellarNet, Inc., Tampa, FL, USA).

\subsection{Fluorescence Quenching}

The Quanta Master ${ }^{\mathrm{TM}} 40$ (from Photon Technology International (PTI), currently a part of Horiba) was used to investigate fluorescent quenching of the 2-amino-4-methyl-6-phenylbenzene-1,3-dicarbonitrile derivatives in the presence of additives (i.e., iodonium salt-Speedcure 938, or ethyl 4-(dimethylamino)benzoate-EDB). In the case of fluorescent quenching with iodine salt (Speedcure 938), the total amount of added quencher was about $2.7 \times 10^{-2} \mathrm{~mol} / \mathrm{dm}^{3}$, and in the case of fluorescent quenching with ethyl 4-(dimethylamino)benzoate (EDB), it was $7.5 \cdot \times 10^{-2} \mathrm{~mol} / \mathrm{dm}^{3}$.

\subsection{Determination of Fluorescent Lifetime}

Fluorescence decay curves were recorded with spectrophotometer EasyLife ${ }^{\mathrm{TM}} \mathrm{X}$ (Fluorescence Lifetime Fluorometer by Photon Technology International (PTI), currently a part of Horiba) using a pulsed LED excitation source at $310 \mathrm{~nm}$. To obtain the IRF instrument response function, the solution of colloidal silica Ludox ${ }^{\circledR}$ (by Sigma Aldrich) highly diluted in water was used as a scatterer. Fluorescent lifetimes were estimated by fitting the decay curves using a deconvolution procedure implemented in Fluorescence Decay Analysis Software. Fluorescence decay curves were fitted with an exponential function to give a lifetime $\tau$.

\subsection{Molecular Orbital Calculations}

Gaussian 09 package was used for calculating the energy gap between the first triplet energy $\left(T_{1}\right)$ and ground state energy $\left(S_{0}\right)$. Firstly, the optimization of $S_{0}$ and $T_{1}$ states was carried out for each of the molecular structures of interest. Optimization of molecules in the ground state and first triplet excited state were performed using the density functional theory (DFT) method at a B3LYP/6-31G (d, p) level of theory. Energy gap was calculated as the difference of the total energy of the molecule in the first triplet excited state $\left(\mathrm{E}_{\mathrm{T} 1}\right)$ and the total energy of the molecule in the ground state $\left(\mathrm{E}_{\mathrm{S} 0}\right)$. The frontier molecular orbitals properties were analyzed and visualized using GaussView 5.0 software. The computational procedures were done by using open infrastructure resources PLGrid Infrastructure. PLGrid Infrastructure enables carrying out scientific research based on the simulations and large-scale calculations using the computing clusters, as well as provides convenient access to distributed computing resources.

\subsection{Monitoring the Photopolymerization Processes by Real-Time FT-IR}

The photopolymerization kinetic was investigated using the real-time FT-IR method, along with FT-IR i10 NICOLET ${ }^{\mathrm{TM}}$ spectrometer with a horizontal adapter (from Thermo Scientific, Waltham, MA, USA). The compositions for photopolymerization measurements were prepared by dissolution of each component in the monomer or mixture of monomers. All compositions were prepared in dark glass vials and stored in the dark until used. The weight percent of the photoinitiating system was calculated from the monomer content. Because the decrease of absorption of the peak area is directly proportional to the number of polymerized groups, the degree of conversion of the function group was calculated by measuring the peak area at each time of the reaction by using Equation (5):

$$
\text { Conversion }[\%]=\left(1-\frac{A_{A f t e r}}{A_{\text {Before }}}\right) * 100 \%
$$

where $A_{\text {Before }}$ is an area of the absorbance peak characteristic for used monomer and type of photopolymerization before polymerization process, and $\mathrm{A}_{\mathrm{After}}$ is an area of the same absorbance 
peak, but after polymerization process. The values of the characteristic absorbance peak for studied monomers are given below for each type of photopolymerization. An excellent solubility was observed in different monomers for all of the biphenyl derivatives.

\subsubsection{Cationic Photopolymerization (CP) of Cycloaliphatic Epoxide Monomers Experiments}

The thin-layer compositions were prepared by dissolution of the photosensitizers and iodonium salt in CADE monomer in such proportions as to obtain concentrations of about $0.1 \mathrm{wt} . \%$ $\left(3,69 \cdot \times 10^{-3} \mathrm{~mol} \cdot \mathrm{dm}^{-3}\right)$ of the appropriate 2-amino-4-methyl-6-phenyl-benzene-1,3-dicarbonitrile derivative and about $1 \mathrm{wt} . \%$ of the iodonium salt $\left(1.9 \cdot \times 10^{-2} \mathrm{~mol} \cdot \mathrm{dm}^{-3}\right.$, Speedcure 938$)$. Before the measurement, one drop of the solution was placed on the $\mathrm{BaF}_{2}$ pallet (the thickness of the composition was $\sim 25 \mu \mathrm{m}$ ). The evaluation of epoxy content was continuously followed under air at about $790 \mathrm{~cm}^{-1}$ for $800 \mathrm{~s}$.

\subsubsection{Cationic Photopolymerization (CP) of Glycidyles Monomers Experiments}

The photocurable composition consisted of the following monomers: Bisphenol A diglycidyl ether (DGEBA) and 1,2-epoxy-3-phenoxypropane (EPXPROP) $(70 \% / 30 \% \mathrm{w} / \mathrm{w})$ in the presence of two component photoinitiating system based on biphenyls derivatives $(0.2 \mathrm{wt} . \%)$ and Speedcure 938 ( $2 \mathrm{wt} . \%)$. A drop of the composition was placed on the $\mathrm{BaF}_{2}$ pallet under air ( $25 \mu \mathrm{m}$ thickness) and the glycidyl group content was fallowed at the changing surface of the band located at $915 \mathrm{~cm}^{-1}$.

\subsubsection{Free-Radical Photopolymerization (FRP) Experiments}

The composition, used for evaluation of initiating properties, contained TMPTA monomer, $1 \mathrm{wt} . \%$ of the iodonium salt $\left(1.9 \cdot \times 10^{-2} \mathrm{~mol} \cdot \mathrm{dm}^{-3}\right.$, Speedcure 938$)$, and $0.1 \mathrm{wt} . \%$ of the investigated biphenyl derivatives. The experiments were carried out in laminated conditions. The composition was applied between two layers of polypropylene films to reduce the oxygen inhibition (the thickness of the composition was $\sim 25 \mu \mathrm{m}$ ). The laminated samples were deposited on a horizontal holder for the FT-IR spectrometer and were irradiated. The evolution of the double bond of acrylate TMPTA content was continuously followed by real-time FT-IR spectroscopy (Nicolet ${ }^{\mathrm{TM}}$ iS10, from Thermo Scientific, Waltham, MA, USA) at about $1635 \mathrm{~cm}^{-1}$.

3.9.4. Free-Radical Photopolymerization with Biphenyl Derivatives/EDB as Type II Bimolecular Photoinitiating System

The formulations of bimolecular free-radical photoinitiator type II were prepared by dissolution of the ethyl 4-(dimethylamino)benzoate (EDB) and each biphenyl derivative in monomer TMPTA to obtain the concentration $1.5 \%$ by weight $\left(1.9 \cdot \times 10^{-2} \mathrm{~mol} \cdot \mathrm{dm}^{-3}\right)$ of the amine and $3.5 \cdot \times 10^{-3} \mathrm{~mol} \cdot \mathrm{dm}^{-3}$ of the 2-amino-4-methyl-6-phenyl-benzene-1,3-dicarbonitrile derivatives. The weight percent of the photoinitiating system was calculated from the monomer content. Free-radical photopolymerization of TMPTA monomer was monitored in laminate condition ( $25 \mu \mathrm{m}$ thickness) by the decrease of the double bond content of acrylate functions, continuously followed by real-time FT-IR spectroscopy (i10 NICOLET ${ }^{\mathrm{TM}}$ spectrometer, Thermo Scientific, Waltham, MA, USA) at the number of wavelength $1635 \mathrm{~cm}^{-1}$.

\subsection{Two-dimensional (2D) Resolution Test}

To test the optical quality of selected samples, we used a USAF resolution test chart as the input image to illuminate a 1.0-mm-thick sample. The resolution test was performed using standard R3L3S1N—Negative 1951 USAF Test Target (from Thermo Scientific, Waltham, MA, USA). The USAF resolution targets consist of bars organized in groups and elements. Each group consists of six elements (i.e., elements 1-6) and each element is composed of three horizontal and three vertical equally spaced bars. Each element within a group corresponds to an associated resolution, based on the bar width/space. The resolution of an imaging system is defined by the group and element before the 
black and white bars start blending together. To determine the limiting resolution of the investigated photocurable compositions, Equation (6) was used. This equation describes the relationship between group number and element number to determine resolution in terms of line pairs per millimeter.

$$
\text { Resolution }[\mathrm{lp} / \mathrm{mm}]=2^{\left(\text {Group number+ } \frac{\text { Element number-1 }}{6}\right)}
$$

For 2D printing experiments, the two component system consisted of 2-amino-4-[4-(4methylsulfanylphenyl)phenyl]-6-methyl-benzene-1,3-dicarbonitrile (B6)/Speedcure $938(0.1 \% / 1 \% \mathrm{w} / \mathrm{w})$ and 2-amino-4-methyl-6-(4-methylsulfanylphenyl)benzene-1,3-dicarbonitrile (B6A)/Speedcure 938 $(0.1 \% / 1 \% \mathrm{w} / \mathrm{w})$.

Various monomers were investigated in terms of formation of the interpenetrating polymer systems and copolymers. The investigated compositions were placed near the imaging lens of the source of light $365 \mathrm{~nm}$ M365LP1 UV-LED (0.7 A, from Thorlabs Inc., Tampa, FL, USA). The photosensitive cationic and free-radical resin was polymerized under air. A schematic illustration of the set-up for determining optical resolution and directly transmitted image of the mask is shown in Scheme 1. All generated patterns from 2D printing were separately analyzed by an optical stereo microscope with stereo zoom objective and magnification in the range of 10-160x (BRESSER Advance ICD 10-160x Zoom Stereo-Microscope, Bresser GmbH, Germany). Real-time FT-IR was used for determination of the conversions for tested compositions. The light source for the real-time FT-IR method was the $365 \mathrm{~nm}$ M365LP1 UV-LED diode (from Thorlabs Inc., Tampa, FL, USA). A similar intensity and emission spectrum for the UV-LED on the surface of the sample in 2D printing and the real-time FT-IR experiments was used in order for the comparison to be possible.

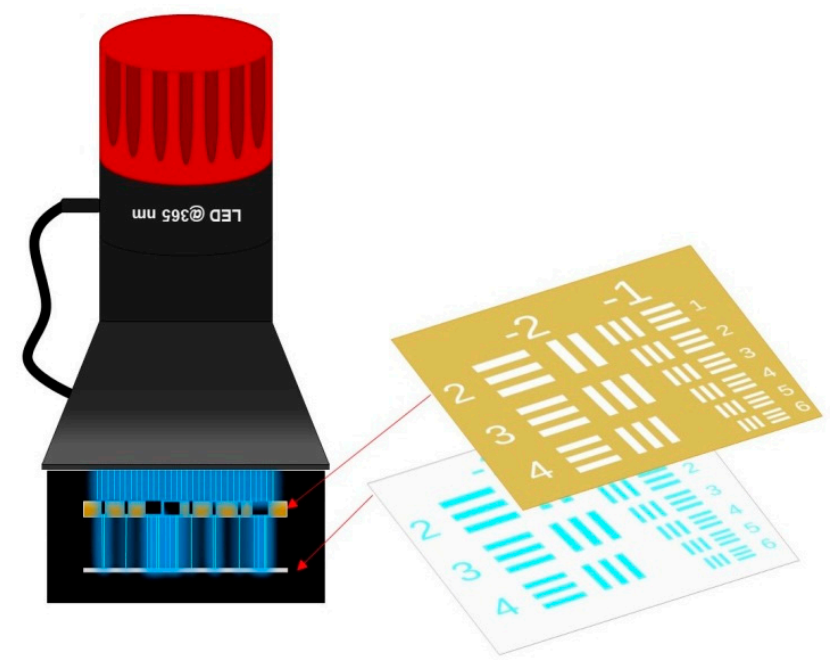

Scheme 1. Schematic set-up for determining optical resolution using the mask transmitted through a 1-mm-thick photopolymer coating.

\subsection{D Printing Experiment}

For 3D printing experiments, the composition consisted of DGEBA/EPXPROP $(70 \% / 30 \% \mathrm{w} / \mathrm{w})$ in the presence of biphenyl derivatives/Speedcure $938(0.1 / 1 \% \mathrm{w} / \mathrm{w})$. A 1-mm-thick photopolymerizable resin in the presence of bimolecular photoinitiating systems was disposed of on a microscope glass. The Laser Engraver Printer machine (NEJE DK-8-KZ) was adapted to the laser write under the intensity of $1500 \mathrm{~mW}$ at $405 \mathrm{~nm}$ with the distance $7 \mathrm{~cm}$ (spot diameter, $\sim 75 \mu \mathrm{m}$ ). The generated 3D objects were observed thanks to an optical stereo microscope (BRESSER Advance ICD 10-160x Zoom Stereo-Microscope, Bresser GmbH, Germany). 


\section{Conclusions}

In conclusion, a new visible light photoinitiating system consisting of biphenyl derivatives and iodonium salt has been designed. The most important feature of this bimolecular photoinitiating system is the use of a UV-A range and also visible light to initiate photopolymerization. As such, it can play an important role in different applications requiring visible light photosensitization. The development of 2-amino-4-methyl-6-phenyl-benzene-1,3-dicarbonitrile derivatives can undergo electron transfer reactions with diaryliodonium salts to yield the corresponding cations for the initiation of the cationic polymerization of epoxide, vinyl, or glycidyl monomers, as well as to generate the radical for the initiation of the free-radical photopolymerization of acrylates and methacrylates. The possibility of initiation of both free-radical and cationic photopolymerization also renders these new versatile bimolecular photoinitiators successful for use in the manufacture of IPNs, and in the photopolymerization of formulations of various types of hybrid monomers in order to produce the copolymers matrix. The high performance of 2-amino-4-methyl-6-phenyl-benzene-1,3-dicarbonitrile derivatives as photosensitizers of iodonium salt in bimolecular photoinitiating systems is also useful in $3 \mathrm{D}$ photocured formulations. The proposed bimolecular photoinitiating systems can be used in 3D printing technology using SLA or DLP techniques. The development of efficient and dual-cure photoinitiating systems is still a huge challenge deserving of scholarly attention. The authors are currently engaged in the development of different high-reactive photosensitive formulations for 3D printing photopolymers, which will be presented in forthcoming papers.

Supplementary Materials: The following are available online at http://www.mdpi.com/2073-4344/9/10/827/s1: Scheme S1: Synthetic path to 2-amino-4-methyl-6-phenyl-benzene-1,3-dicarbonitriles; Scheme S2: Synthetic path to 2-amino-4-methyl-6-(4-phenylphenyl)benzene-1,3-dicarbonitriles; Figures S1-S28: Cyclic voltammogram curves of the 2-amino-4-methyl-6-phenyl-benzene-1,3-dicarbonitrile derivatives' oxidation and reduction in acetonitrile; Figures S29-S42: Emission and excitation spectra for the determination of the excited singlet state energy for 2-amino-4-methyl-6-(4-phenylphenyl)benzene-1,3-dicarbonitriles; Figures S43-S70: Fluorescence quenching and Stern-Volmer treatment of 2-amino-4-methyl-6-(4-phenylphenyl)benzene-1,3-dicarbonitriles and Speedcure 938; Figures S71-S98: Fluorescence quenching and Stern-Volmer treatment of 2-amino-4-methyl-6-(4-phenylphenyl)benzene-1,3-dicarbonitriles and EDB; Figure S99: Photolysis of B6 in ACN under $365 \mathrm{~nm}\left(190 \mathrm{~mW} / \mathrm{cm}^{2}\right)$; Figure S100: Photolysis of B6 + Speedcure 938 (concentration: $1.59 \cdot \times 10^{-3}\left[\mathrm{~mol} / \mathrm{dm}^{3}\right]$ ) in ACN under $365 \mathrm{~nm}\left(190 \mathrm{~mW} / \mathrm{cm}^{2}\right)$; Figure S101: Photolysis of B6A in ACN under $365 \mathrm{~nm}(190 \mathrm{~mW} / \mathrm{cm} 2)$; Figure S102: Photolysis of B6A + Speedcure 938 (concentration: $1.59 \cdot \times 10^{-3}\left[\mathrm{~mol} / \mathrm{dm}^{3}\right]$ ) in ACN under $365 \mathrm{~nm}$ $\left(190 \mathrm{~mW} / \mathrm{cm}^{2}\right)$; Figures S103-S126: Photopolymerization profiles carried out in laminate for the system of various photopolymerization processes during the formation of interpenetrating polymer networks with the use of photoinitiating system based on Speedcure 938 and 2-amino-4-methyl-6-phenyl-benzene-1,3-dicarbonitrile derivatives in the role of photosensitizers; Figures S127-S141: ${ }^{1} \mathrm{H}$ NMR spectra of synthesized compounds; Figures S142-S156: ${ }^{13} \mathrm{C}$ NMR spectra of synthesized compounds.

Author Contributions: J.O. conceived the project, designed the research, designed the new photosensitizers, contributed to all aspects of the study, analyzed the whole data sets, and wrote the paper. W.T. performed all of the photopolymerization experiments (including 2D printing and 3D printing) and the photophysical characterizations of the new photosensitizers, and also assisted in writing and editing the manuscript. A.C.-B. performed the synthesis of the different biphenyl derivatives reported in this work and characterized the chemical structures of these photosensitizers by usual techniques. M.P. performed the electrochemistry research and molecular orbital calculations. All authors read and approved the final manuscript.

Funding: This research was funded by the Foundation for Polish Science (Warsaw, Poland) TEAM TECH project Grant No. TEAM TECH/2016-2/15 (POIR.04.04.00-00-204B/16-00) "Molecular design, synthesis and application of photoinitiator-catalysts (PICs) for photopolymerization reactions". The authors are also grateful to the National Centre for Research and Developments-Project TANGO 2 [Grant No. TANGO2/340229/NCBR/2017, 2017] for financing some part of the synthetic research, and to the National Science Centre-Project SONATA [Grant No. UMO-2012/07/D/ST5/02300, 2012] for financing the purchase of steady-state fluorescence spectrofluorometer and real-time FT-IR spectrometer. The computational procedures were done by using open infrastructure resources PLGrid Infrastructure.

Conflicts of Interest: There are no conflicts to declare. 


\section{References}

1. Yagaci, Y.; Jockusch, S.; Turro, N.J. Photoinitiated Polymerization: Advances, and Challenges Opportunities. Macromolecules 2010, 43, 6245-6260. [CrossRef]

2. Chatani, S.; Kloxin, C.J.; Bowman, C.N. The power of light in polymer science: Photochemical processes to manipulate polymer formation, structure, and properties. Polym. Chem. 2014, 7, 2187-2201. [CrossRef]

3. Schwalm, R. UV Coatings: Basics, Recent Developments and New Applications, 1st ed.; Elsevier: Amsterdam, The Netherlands, 2006; pp. 19-61.

4. Schnabel, W. Polymers and Light: Fundamentals and Technical Applications, 1st ed.; Wiley-VCH: Weinheim, Germany, 2008; pp. 273-304.

5. Bean, A.J. Radiation Curing of Printing Inks. In Radiation Curing, Science and Technology, 1st ed.; Pappas, S.P., Ed.; Springer: New York, NY, USA, 1992; pp. 301-332.

6. Czech, Z.; Kowalczyk, A.; Ortyl, J.; Świderska, J. Acrylic Pressure-Sensitive Adhesives Containing $\mathrm{SiO}_{2}$ Nanoparticles. Pol. J. Chem. Technol. 2013, 15, 12-14. [CrossRef]

7. Do, H.S.; Park, Y.J.; Kim, H.J. Preparation and adhesion performance of UV-crosslinkable acrylic pressure sensitive adhesives. J. Adhes. Sci. Technol. 2006, 20, 1529-1545. [CrossRef]

8. Crivello, J.V.; Reichmanis, E. Photopolymer Materials and Processes for Advanced Technologies. Chem. Mater. 2014, 26, 533-548. [CrossRef]

9. Sanders, D.P. Advances in Patterning Materials for $193 \mathrm{~nm}$ Immersion Lithography. Chem. Rev. 2010, 110, 321-360. [CrossRef]

10. Baroli, B. Photopolymerization of biomaterials: Issues and potentialities in drug delivery, tissue engineering, and cell encapsulation applications. J. Chem. Technol. Biotechnol. 2006, 81, 491-499. [CrossRef]

11. Nguyen, K.T.; West, J.L. Photopolymerizable hydrogels for tissue engineering applications. Biometerials 2002, 23, 4307-4314. [CrossRef]

12. Fisher, J.P.; Dean, D.; Engel, P.S.; Mikos, A.G. Photoinitiated Polymerization of Biomaterials. Annu. Rev. Mater. Res. 2001, 31, 171-181. [CrossRef]

13. Jandt, K.D.; Singusch, B.W. Future perspectives of resin-based dental materials. Dent. Mater. 2009, 25, 1001-1006. [CrossRef]

14. Vitale, A.; Sangermano, M.; Bongiovanni, R.; Burtscher, P.; Moszner, N. Visible Light Curable Restorative Composites for Dental Applications Based on Epoxy Monomer. Materials 2014, 7, 554-562. [CrossRef] [PubMed]

15. Nakamura, K. Photopolymers: Photoresist Materials, Processes, and Applications, 1st ed.; CRC Press: Boca Raton, FL, USA, 2015; pp. 97-118.

16. Bunning, T.J.; Natarajan, V.P.; Tondiglia, V.P.; Sutherland, R.L. Holographic Polymer-Dispersed Liquid Crystals (H-PDLCs). Annu. Rev. Mater. Sci. 2000, 30, 83-115. [CrossRef]

17. Stropp, J.P.; Wolff, U.; Löffler, H.; Osterhold, M.; Thomas, H. UV curing systems for automotive refinish applications. Prog. Org. Coat. 2006, 55, 201-205. [CrossRef]

18. Dietliker, K.; Braig, A.; Ricci, A. Industrial applications of photochemistry: Automotive coatings and beyond. In Photochemistry, 1st ed.; Albini, A., Ed.; Royal Society of Chemistry: London, UK, 2010; Volume 48, pp. 344-368.

19. Guo, J.; Gleeson, M.R.; Sheridan, J.T. A Review of the Optimisation of Photopolymer Materials for Holographic Data Storage. Phys. Res. Int. 2012, 2012,1-16. [CrossRef]

20. Vitale, A.; Quaglio, M.; Cocuzza, M.; Pirri, C.F.; Bongiovanni, R. Photopolymerization of a perfluoropolyether oligomer and photolithographic processes for the fabrication of microfluidic devices. Eur. Polym. J. 2012, 48, 1118-1126. [CrossRef]

21. Haraldsson, K.T.; Hutchison, J.B.; Sebra, R.P.; Good, B.T.; Anseth, K.S.; Bowman, C.N. 3D polymeric microfluidic device fabrication via contact liquid photolithographic polymerization (CLiPP). Sens. Actuators $B$ 2006, 113, 454-460. [CrossRef]

22. Ligon, S.C.; Liska, R.; Stampfl, J.; Gurr, M.; Mülhaupt, R. Polymers for 3D Printing and Customized Additive Manufacturing. Chem. Rev. 2017, 117, 10212-10290. [CrossRef]

23. Layani, M.; Wang, X.; Magdassi, S. Novel Materials for 3D Printing by Photopolymerization. Adv. Mater. 2018, 30, 1706344. [CrossRef]

24. Bagheri, A.; Jin, J. Photopolymerization in 3D Printing. Appl. Polym. Mater. 2019, 1, 593-611. [CrossRef] 
25. Tumbleston, J.R.; Shirvanyants, D.; Ermoshkin, N.; Janusziewicz, R.; Johnson, A.R.; Kelly, D.; Chen, K.; Pinschmidt, R.; Rolland, J.P.; Ermoshkin, A.; et al. Continuous liquid interface production of 3D objects. Science 2015, 347, 1349-1352. [CrossRef]

26. Kostrzewska, K.; Ortyl, J.; Dobosz, R.; Kabatc, J. Squarylium dye and onium salts as highly sensitive photoradical generators for blue light. Polym. Chem. 2017, 6, 3464-3474. [CrossRef]

27. Andrzejewska, E. Photopolymerization Kinetics of Multifunctional Monomers. Prog. Polym. Sci. 2001, 26, 605-665. [CrossRef]

28. Ligon, S.C.; Husár, B.; Wutzel, H.; Holman, R.; Liska, R. Strategies to Reduce Oxygen Inhibition in Photoinduced Polymerization. Chem. Rev. 2013, 114, 557-589. [CrossRef]

29. Ortyl, J. Cationic Photoinitiators. In Photopolymerisation Initiating Systems, 1st ed.; Lalevée, J., Fouassier, J.P., Eds.; Royal Society of Chemistry: Croydon, UK, 2018; pp. 74-130.

30. Sangermano, M.; Rappolo, I.; Chiappone, A. New Horizons in Cationic Photopolymerization. Polymers 2018, 10, 136. [CrossRef] [PubMed]

31. Ortyl, J.; Popielarz, R. New photoinitiators for cationic polymerization. Polimery 2012, 57, 7-8. [CrossRef]

32. Kabatc, J.; Ortyl, J.; Kostrzewska, K. New kinetic and mechanistic aspects of photosensitization of iodonium salts in photopolymerization of acrylates. RCV Adv. 2017, 66, 41619-41629. [CrossRef]

33. Crivello, J. Cationic Polymerization-Iodonium and Sulfonium Salt Photoinitiators. Adv. Polym. Sci. 2006, 63, $1-48$.

34. Mousawi, A.A.; Dietlin, C.; Graff, B.; Morlet-Savary, F.; Toufaily, J.; Hamieh, T.; Fouassier, J.P.; Chachaj-Brekiesz, A.; Ortyl, J.; Lalevée, J. Meta-Terphenyl Derivative/Iodonium Salt/9H-Carbazole-9-ethanol Photoinitiating Systems for Free Radical Promoted Cationic Polymerization upon Visible Lights. Macromol. Chem. Phys 2016, 217, 1955-1965. [CrossRef]

35. Matyjaszewski, K.; Sawamto, M. Controlled/Living Carbocationic Polymerization. In Cationic Polymerizations: Mechanisms, Synthesis \& Applications, 1st ed.; Matyjaszewski, K., Ed.; Marcel Dekker: New York, NY, USA, 1996; pp. 265-380.

36. Ortyl, J.; Wilamowski, J.; Milart, P.; Galek, M.; Popielarz, R. Relative Sensitization Efficiency of Fluorescent Probes/Sensitizers for Monitoring and Acceleration of Cationic Photopolymerization of Monomers. Polym. Test. 2015, 48, 151-159. [CrossRef]

37. Fouassier, J.P.; Lalevée, J. Photochemical Production of Interpenetrating Polymer Networks; Simultaneous Initiation of Radical and Cationic Polymerization Reactions. Polymers 2014, 6, 2588-2610. [CrossRef]

38. Kaczmarek, H.; Decker, C. Interpenetrating polymer networks. I. Photopolymerization of multiacrylate systems. J. Appl. Polym. Sci. 1994, 54, 2147-2156. [CrossRef]

39. Decker, C.; Bendaikha, T. Interpenetrating polymer networks. II. Sunlight-induced polymerization of multifunctional acrylates. J. Appl. Polym. Sci. 1998, 70, 2269-2282. [CrossRef]

40. Rajaraman, S.K.; Mowers, W.A.; Crivello, J.V. Interaction of epoxy and vinyl ethers during photoinitiated cationic polymerization. J. Polym. Sci. A 2000, 37, 40007-44018. [CrossRef]

41. Nowak, D.; Ortyl, J.; Kamińska-Borek, I.; Kukuła, K.; Topa, M.; Popielarz, R. Photopolymerization of hybrid monomers: Part I: Comparison of the performance of selected photoinitiators in cationic and free-radical polymerization of hybrid monomers. Polym. Test. 2017, 64, 310-320. [CrossRef]

42. Nowak, D.; Ortyl, J.; Kamińska-Borek, I.; Kukuła, K.; Topa, M.; Popielarz, R. Photopolymerization of hybrid monomers, Part II: Determination of relative quantum efficiency of selected photoinitiators in cationic and free-radical polymerization of hybrid monomers. Polym. Test. 2018, 67, 144-150. [CrossRef]

43. McCoy, J.D.; Ancipink, W.B.; Clarkson, C.M.; Kropka, J.M.; Celina, M.C.; Giron, N.H.; Hailesilassie, L.; Fredj, N. Cure mechanisms of diglycidyl ether of bisphenol A (DGEBA) epoxy with diethanolamine. Polymer 2016, 105, 243-254. [CrossRef]

44. Chen, H.; Cong, P.; Su, C.; Li, T. Curing Behavior and Mechanism of Diglycidyl Ether of Bisphenol-A in the Presence of Poly (Amide-Amidic Acid) and 4,4'-Diaminodiphenylsulfone. J. Macromol. Sci. B 2014, 53, 735-748. [CrossRef]

45. Ghaemy, M.; Riahy, M.H. Kinetics of anhydride and polyamide curing of bisphenol A-based diglycidyl ether using DSC. Eur. Polym. J. 1996, 32, 1207-1212. [CrossRef]

46. Crivello, J.V.; Walton, T.C.; Malik, R. Fabrication of Epoxy Matrix Composites by Electron Beam Induced Cationic Polymerization. Chem. Mater. 1997, 9, 1273-1284. [CrossRef] 
47. Bulut, U.; Crivello, J.V. Investigation of the Reactivity of Epoxide Monomers in Photoinitiated Cationic Polymerization. Macromolecules 2005, 38, 3584-3595. [CrossRef]

48. Bi, Y.; Neckers, D.C. A Visible Light Initiating System for Free Radical Promoted Cationic Polymerization. Macromolecules 1994, 27, 3683-3693. [CrossRef]

49. Lakowicz, J.R. Principles of Fluorescence Spectroscopy, 3rd ed.; Springer: New York, NY, USA, 2006; pp. 278-330.

50. Fouassier, J.P.; Lalevee, J. Photoinitiators for Polymer Synthesis-Scope, Reactivity and Efficiency, 1st ed.; Wiley-VCH: Weinheim, Germany, 2012; pp. 103-123.

51. Romańczyk, P.P.; Kurek, S.S. The Reduction Potential of Diphenyliodonium Polymerisation Photoinitiator Is Not -0.2 V vs. SCE. A Computational Study. Electrochim. Acta. 2017, 225, 482-485. [CrossRef]

52. Strehmel, B.; Ernst, S.; Reiner, K.; Keil, D.; Lindauer, H.; Baumann, H. Application of NIR-photopolymers in the graphic industry: From physical chemistry to lithographic applications. Z. Phys. Chem. 2014, 228, 129-153. [CrossRef]

53. Andrzejewska, E.; Zych-Tomkowiak, D.; Andrzejewski, M.; Hug, G.L.; Marciniak, B. Heteroaromatic Thiols as Co-initiators for Type II Photoinitiating Systems Based on Camphorquinone and Isopropylthioxanthone. Macromolecules 2006, 369, 3777-3785. [CrossRef]

(C) 2019 by the authors. Licensee MDPI, Basel, Switzerland. This article is an open access article distributed under the terms and conditions of the Creative Commons Attribution (CC BY) license (http://creativecommons.org/licenses/by/4.0/). 